\title{
Group 13 decamethylmetallocenium cations $\dagger$
}

\section{Charles L. B. Macdonald, + John D. Gorden, $\oint$ Andreas Voigt, Silvia Filipponi and Alan H. Cowley*}

\author{
Received 22nd October 2007, Accepted 6th November 2007 \\ First published as an Advance Article on the web 18th December 2007 \\ DOI: $10.1039 / \mathrm{b} 716220 \mathrm{k}$
}

\begin{abstract}
Salts containing the decamethylmetallocenium cations, $\left[\left(\mathrm{C}_{5} \mathrm{Me}_{5}\right)_{2} \mathrm{M}\right]^{+}\left(\right.$or $\left.\mathrm{Cp}_{2}{ }_{2} \mathrm{M}^{+}\right)$of the group 13 "metals" B, Al and Ga have been prepared using a variety of synthetic routes. Precursor molecules of the type $\mathrm{Cp}_{2}{ }_{2} \mathrm{MX}(\mathrm{X}=\mathrm{Cl}, \mathrm{Br}, \mathrm{Me})$ exhibit structural features that vary significantly depending on the size and electronegativity of the central atom. While salt metathesis, halide abstraction and methanide abstraction methods represent viable routes for the preparation of salts of $\mathrm{Cp}^{*}{ }_{2} \mathrm{~B}^{+}$and $\mathrm{Cp}^{*}{ }_{2} \mathrm{Al}^{+}$, acidolysis of a Cp* group from $\mathrm{Cp}_{3}{ }_{3} \mathrm{Ga}$ is the most reliable method for the synthesis of the analogous gallium cation. Gallocenium cations are less stable than either of the lighter congeneric cations since they prove to be susceptible to decomposition reactions involving the "back-transfer" of ligands from the counter anion. Density functional theory (DFT) calculations revealed that, whereas $\mathrm{Cp}_{2}{ }_{2} \mathrm{Ga}^{+}$is predicted to adopt a molecular structure more similar to that of $\mathrm{Cp}^{*}{ }_{2} \mathrm{~B}^{+}$, the electronic structure of the gallium cation bears a greater resemblance to that of $\mathrm{Cp}_{2}{ }_{2} \mathrm{Al}^{+}$.
\end{abstract}

\section{Introduction}

The past decade has witnessed an upsurge of interest in the chemistry of main-group metallocenes. ${ }^{1}$ Much less is known, however, about main group metallocenes than their transition metal counterparts but interest in this general area has been stimulated by the recent report of the pseudo-main group compounds $\mathrm{Cp}^{\prime}-$ $\mathrm{Zn}-\mathrm{Zn}-\mathrm{Cp}^{\prime}\left(\mathrm{Cp}^{\prime}=\mathrm{C}_{5} \mathrm{Me}_{4} \mathrm{R} ; \mathrm{R}=\mathrm{Me}, \mathrm{Et}\right){ }^{2}$ the first metallocenes to feature two metals sandwiched between cyclopentadienide rings. From a practical standpoint, research into the chemistry of maingroup metallocenes has been driven by their utility as reagents and as chemical vapor deposition sources. ${ }^{3}$ Moreover, attention has been drawn to the possibility that cationic main group metallocene species might serve as useful activators, initiators or catalysts for, e.g., alkene polymerization. ${ }^{4}$ In the context of group 13 metallocene chemistry, structurally authenticated cations represent a relatively recent development and show an unprecedented diversity of structural and chemical characteristics. For example, the decamethylborocenium cation $\left(1^{+}\right)^{5,6}$ features an unusual "tightly squeezed" $\eta^{5} / \eta^{1}$ structure while the decamethylaluminocenium cation $\left(\mathbf{2}^{+}\right),{ }^{7-13}$ possesses a ferrocene-like structure. Interestingly, the parent aluminocenium cation $\mathrm{Cp}_{2} \mathrm{Al}^{+}$has been shown to serve as a potent activation for olefin polymerization. ${ }^{4}$ The sole example of a decamethylgallocenium cation $\left(\mathbf{3}^{+}\right)$is much less stable than either of its lighter congeners and possesses a unique $\eta^{3} / \eta^{1}$ structure that appears to be a consequence of close cation-anion interactions. ${ }^{14}$ In the present article, we summarize

Department of Chemistry and Biochemistry, The University of Texas at Austin, 1 University Station A5300, Austin, TX, 78712, USA. E-mail: cowley@mail.utexas.edu; Fax: +1512 471-6822; Tel: +1512 471-7484 $\dagger$ CCDC reference numbers 199049, 664840-665221. For crystallographic data in CIF or other electronic format see DOI: $10.1039 / \mathrm{b} 716220 \mathrm{k}$

$\$$ Present address: Department of Chemistry and Biochemistry, The University of Windsor, 401 Sunset Ave., Windsor, Ontario, Canada N9B $3 \mathrm{P} 4$.

$\S$ Present address: Department of Chesmistry, Auburn University, 179 Chemistry Building, Auburn, AL 36840, USA. the results of our various investigations which, when combined with new DFT calculations and pertinent literature examples, provide a more complete understanding of this unparalleled series of isovalent sandwich compounds and their precursors.

\section{Results and discussion}

\section{Metallocenium cation precursors}

The structures, bonding and reactivity patterns of the precursors to the group 13 metallocenium cations provide many insights into the nature of the cations formed therefrom, hence a thorough examination of such compounds represents an important component of the theme of group 13 decamethylmetallocenium chemistry. Although the syntheses or structures of some of the compounds reported herein have been presented in previous contributions from our group and those of other colleagues, the area is of sufficient topical interest to warrant a more comprehensive discussion.

The bis(pentamethylcyclopentadienyl)haloboranes $\mathrm{Cp}_{2}^{*} \mathrm{BX}$ $[(\mathrm{X}=\mathrm{Cl}(\mathbf{4}), \mathrm{Br}(\mathbf{5})]$ are conveniently synthesized in high yields by treatment of $\mathrm{BX}_{3}$ with two equivalents of $\mathrm{Cp}^{*} \mathrm{Li}^{15}$ The ${ }^{1} \mathrm{H}$ NMR spectrum of each of these haloboranes exhibits only a single signal for the protons on the $\mathrm{Cp}^{*}$ ring. Likewise, the ${ }^{13} \mathrm{C}$ NMR spectra evidence only two resonances (one for the methyl carbons and one for the ring carbons). The equivalence of the ipso, $\alpha$ and $\beta$ positions of the $\mathrm{Cp}^{*}$ substituents in these NMR spectra is typical of p-block metallocenes and is usually ascribed to rapid 1,2-sigmatropic rearrangements. ${ }^{1}$ The positive ion chemical ionization (CI) mass spectra of $\mathbf{4}$ and $\mathbf{5}$ show peaks attributable to the parent compounds as well as those due to daughter cations of the form $\mathrm{Cp}_{2}{ }_{2} \mathrm{~B}^{+}$and $\mathrm{Cp}^{*} \mathrm{BX}^{+}$. Since $\mathrm{Cp}^{*}{ }_{2} \mathrm{BF}$ represented the only example of a structurally characterized bis(pentamethylcyclopentadienyl)boron halide, ${ }^{15}$ we decided to carry out single-crystal X-ray diffraction studies of 4 and 5. Recrystallization of these compounds from hexane solution afforded block-shaped crystals that were suitable for X-ray diffraction experiments. Details of the data collection, 
Table 1 Crystallographic data for compounds 4, 5, 6, 8 and 11

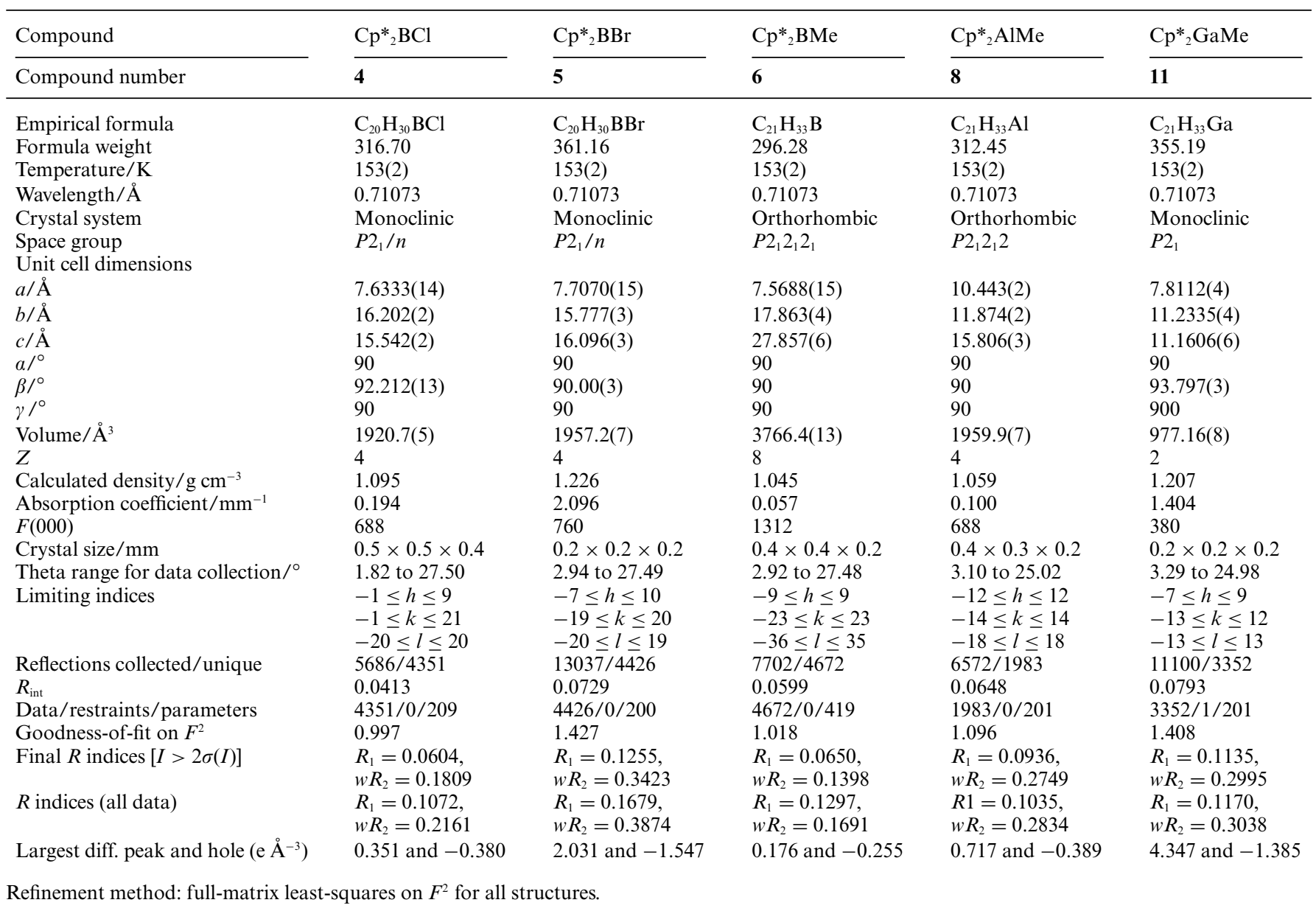

structure solution and refinement are assembled in Table 1 and selected metrical parameters are listed in Table 2. The molecular structures of $\mathbf{4}$ and $\mathbf{5}$ are virtually identical with that of $\mathrm{Cp}_{2}{ }_{2} \mathrm{BF}$ but quite distinct from those of their heavier congeners (vide infra). As illustrated in Fig. 1, each haloborane possesses a monomeric structure of approximately $C_{2}$ symmetry with respect to the $\mathrm{B}-\mathrm{X}$ axis. Each $\mathrm{Cp}^{*}$ ring is sigma-bonded to the boron atom, as evidenced by the $\mathrm{C}_{\text {methyl }}-\mathrm{C}_{i p s o}-\mathrm{B}$ angles $\left(114.7(3)^{\circ}\right)$ and the diene-type structure of the cyclopentadienyl ring. For example, the average $\mathrm{C}_{i p s o}-\mathrm{C}_{\alpha}$ distance $(1.521 \AA)$ in $\mathbf{4}$ is indicative of the
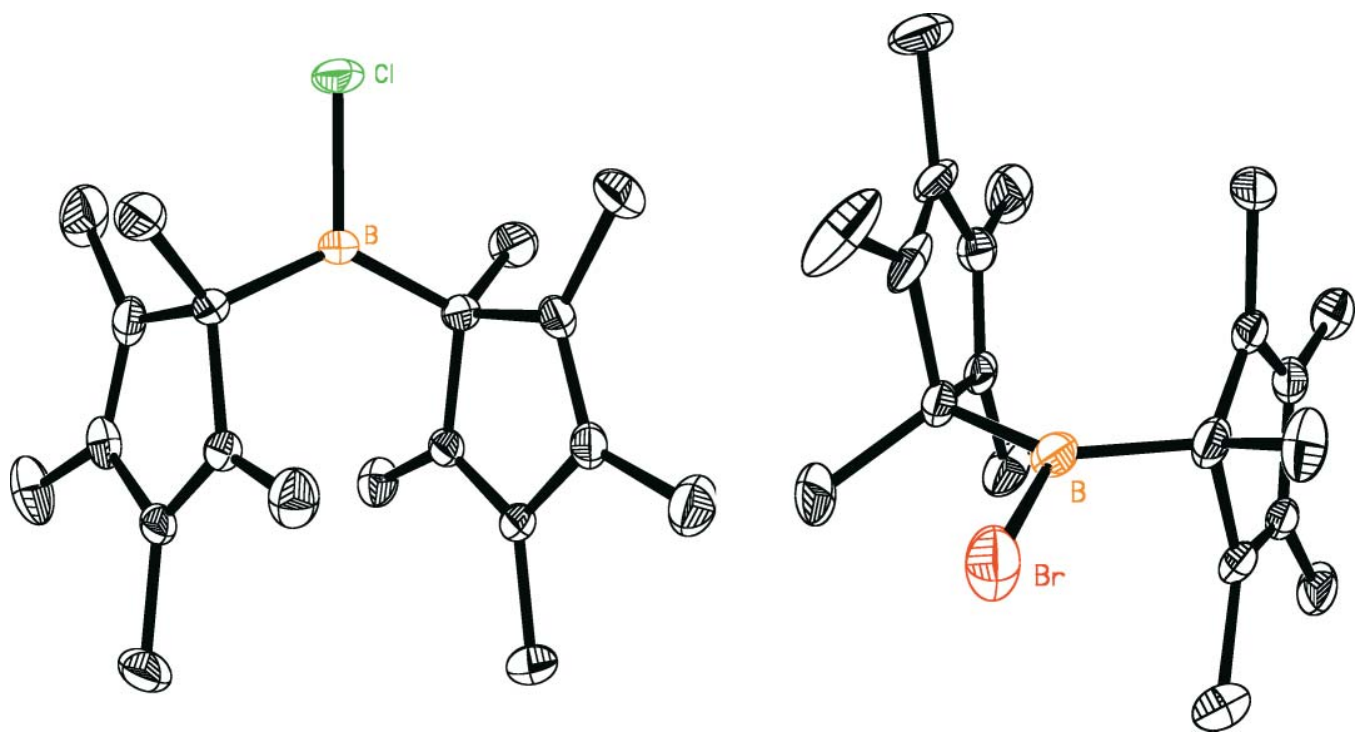

Fig. 1 Thermal ellipsoid plots (30\% probability surface) for $\mathbf{4}$ (left) and $\mathbf{5}$ (right). 
Table 2 Selected bond distances $(\AA)$ and angles $\left({ }^{\circ}\right)$ for 4, 5, 6, 8 and 11

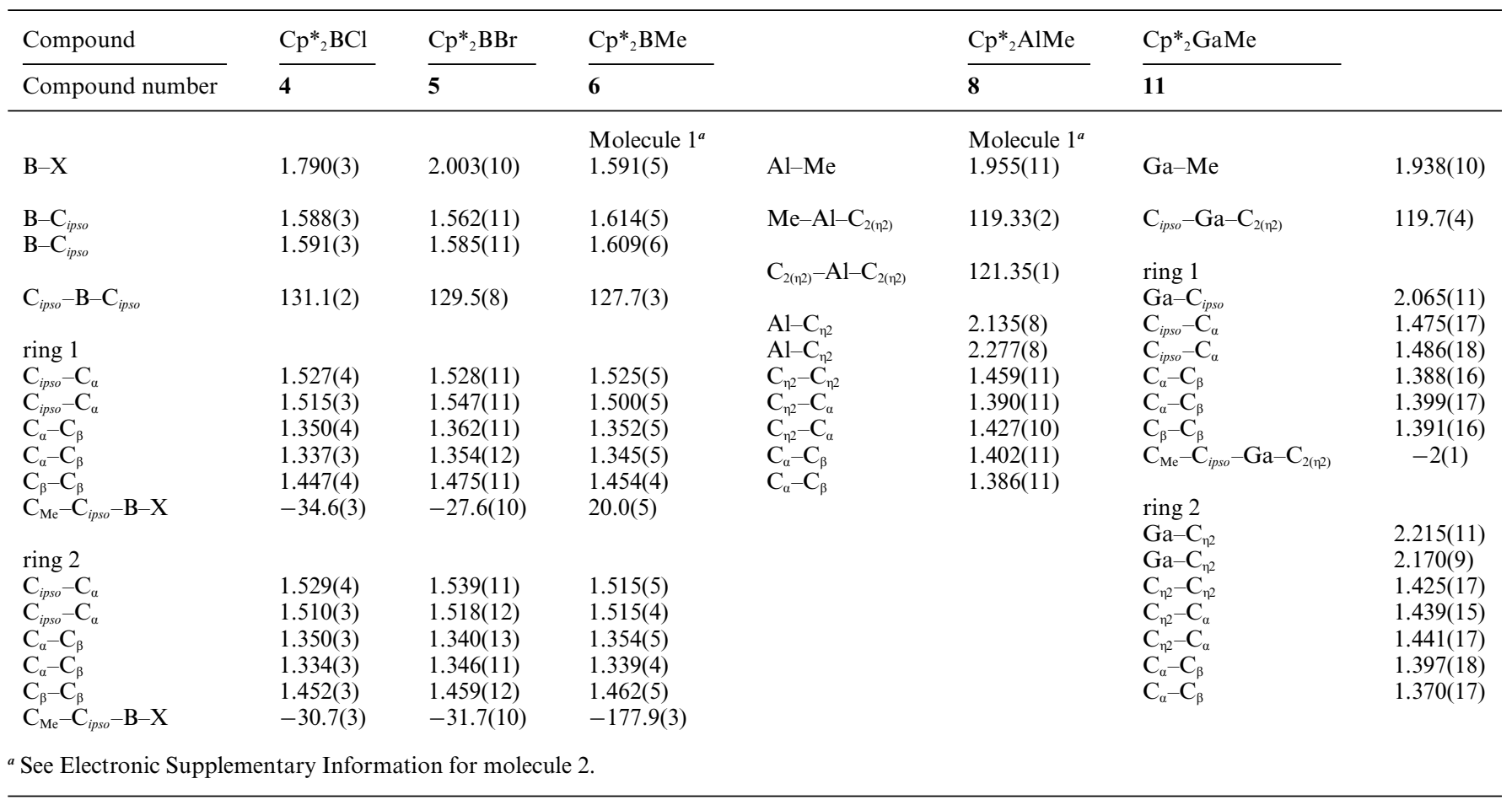

presence of single bonds whereas the average $\mathrm{C}_{\alpha}-\mathrm{C}_{\beta}$ distances $(1.341 \AA)$ and the $\mathrm{C}_{\beta}-\mathrm{C}_{\beta}$ distance $(1.445 \AA)$ are typical of a conjugated diene moiety. However, the most intriguing feature of the haloborane structures relates to the unusual arrangement of the $\mathrm{Cp}^{*}$ substituents, both of which are twisted about the $\mathrm{C}_{i p s o}-\mathrm{B}$ bonds in opposite directions such that the average $\mathrm{C}_{\text {methyl }}-\mathrm{C}_{i p s o}-\mathrm{B}-$ $\mathrm{X}$ torsion angles are $32.1^{\circ}$ for $\mathbf{4}$ and $29.3^{\circ}$ for $\mathbf{5}$. This particular arrangement of $\mathrm{Cp}^{*}$ rings is not a feature of the structures of any of the heavier congeners (vide infra) and is a consequence of the small size of the $\mathrm{B}^{3+}$ cation. The distance between the planes of the two Cp* rings in 4 is only $3.001 \AA$ ( $2.966 \AA$ in 5), which is considerably shorter than the $3.35 \AA$ interplane distance in graphite. As $w^{6}$ and others ${ }^{16,17}$ have postulated previously for $\mathrm{Cp}_{2}{ }_{2} \mathrm{~B}^{+}$, and the isoelectronic $\mathrm{Cp}_{2}{ }_{2} \mathrm{Be}$ analogues, ${ }^{18}$ the minimization of repulsion between the $\pi$-clouds on the $\mathrm{Cp}$ rings is an important factor that affects the arrangement adopted by the $\mathrm{Cp}$ rings in such systems.

Treatment of haloboranes $\mathbf{4}$ or $\mathbf{5}$ with methyllithium provides access to bis(pentamethylcyclopentadienyl)methylborane $\left(\mathrm{Cp}^{*}{ }_{2} \mathrm{BMe}\right) 6$ in high yield. ${ }^{19}$ As observed for the haloborane precursors, the ${ }^{1} \mathrm{H}$ and ${ }^{13} \mathrm{C}$ NMR spectra of 6 exhibit peaks that are indicative of a single $\mathrm{Cp}^{*}$ environment. However, while the solution NMR data are consistent with the presence of two equivalent $\mathrm{Cp}^{*}$ rings in $\mathbf{6}$, the solid-state structure (Fig. 2) reveals two quite distinct ring environments. Although we have published X-ray crystallographic data for $\mathbf{6}$ previously, ${ }^{19}$ there was no listing or discussion of the structural parameters. The crystalline state of $\mathbf{6}$ comprises two crystallographically independent molecules in the asymmetric unit; however, their structures are essentially identical. Selected metrical parameters are listed in Table 2 (in the following text, the data for the second independent molecule are placed in brackets). Although each $\mathrm{Cp}^{*}$ ring of 6 is $\eta^{1}$ $(\sigma)$-bonded to the boron center as evidenced by the metrical

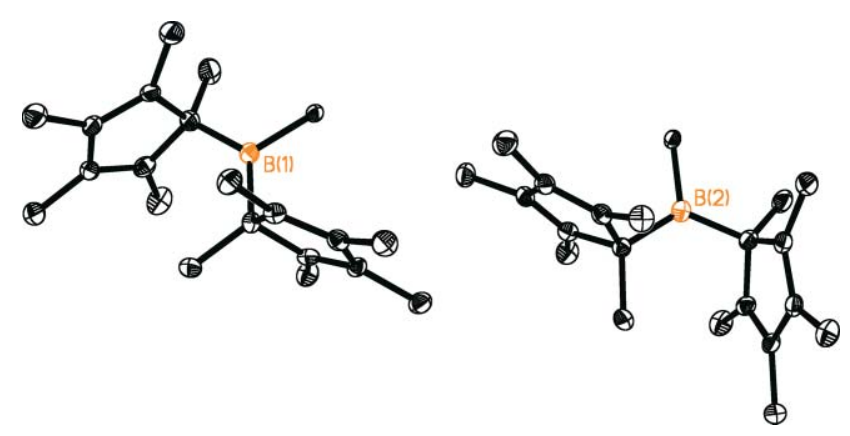

Fig. 2 Thermal ellipsoid plot (30\% probability surface) for 6 .

parameters, the orientation of each ring is distinct and the overall geometry is unlike that of any other bis-cyclopentadienyl compound. For the ring labeled $\mathrm{C}(11)$ to $\mathrm{C}(15)[\mathrm{C}(21)$ to $\mathrm{C}(25)]$ the $\mathrm{C}_{\text {methyl }}-\mathrm{C}_{\text {ipso }}-\mathrm{B}$ angle $\left(114.2(3)^{\circ}\left[113.4(2)^{\circ}\right]\right)$ and the localized $\pi$ structure of the cyclopentadienyl ring suggest $\eta^{1}(\sigma)$ bonding. For example, the average $\mathrm{C}_{i p s o}-\mathrm{C}_{\alpha}$ distances $(1.513 \AA$ $\left.\left[\begin{array}{ll}1.519 & \AA\end{array}\right]\right)$ are indicative of single bonds whereas the $\mathrm{C}_{\beta}-\mathrm{C}_{\beta}$ distance $(1.454(5) \AA[1.463(5) \AA])$ and the average $\mathrm{C}_{\alpha}-\mathrm{C}_{\beta}$ distances $(1.349 \AA$ [1.355 $\AA$ ] ) are characteristic of a conjugated diene fragment. This first $\mathrm{Cp}^{*}$ ligand is oriented in a similar manner to those in the haloboranes $\mathbf{4}$ and $\mathbf{5}$ as indicated by the $\mathrm{C}_{\text {methyl }}-\mathrm{C}_{i p s o}-\mathrm{B}-\mathrm{C}_{\text {methyl }}$ torsion angle of $20.5(5)^{\circ}\left[21.1(5)^{\circ}\right]$. The localized $\pi$-structure of the cyclopentadienyl ring labeled $\mathrm{C}(16)$ $\mathrm{C}(10)[\mathrm{C}(26)-\mathrm{C}(20)]$ is again consistent with $\eta^{1}(\sigma)$-bonding: the average $\mathrm{C}_{i p s o}-\mathrm{C}_{\alpha}$ distances $(1.515 \AA$ [1.519 $\AA$ ] ) are typical of single bonds whereas the $\mathrm{C}_{\beta}-\mathrm{C}_{\beta}$ distance $(1.461(5) \AA[1.463(5) \AA])$ and the average $\mathrm{C}_{\alpha}-\mathrm{C}_{\beta}$ distances $(1.347 \AA[1.353 \AA])$ are characteristic of a conjugated diene fragment. In contrast to the first ring, the second $\mathrm{Cp}^{*}$ ligand is oriented in the opposite sense to those in the 
haloboranes as indicated by the $\mathrm{C}_{\text {methyl }}-\mathrm{C}_{i p s o}-\mathrm{B}-\mathrm{C}_{\text {methyl }}$ torsion angle of $177.9(3)^{\circ}\left[177.6(3)^{\circ}\right]$. The more obtuse $\mathrm{C}_{\text {methyl }}-\mathrm{C}_{i p s o}-\mathrm{B}$ angle $\left(120.9(3)^{\circ}\left[121.2(3)^{\circ}\right]\right)$ is also noteworthy. The orientation adopted by the $\mathrm{Cp}^{*}$ ring places the $\pi$-cloud of this ring in proximity to the formally vacant $2 \mathrm{p}$ orbital on the boron atom thereby allowing for donation from the former to the latter. We postulate that the need for such an interaction is a consequence of the replacement of the $\pi$-donating halide with an essentially non-donating methyl group.

The heavier congeners of $\mathbf{4}, 5$ and $\mathbf{6}$ exhibit significantly different behavior and structural properties in comparison with the corresponding boranes. Although a single crystal X-ray investigation of " $\mathrm{Cp}^{*}{ }_{2} \mathrm{AlCl}$ " (7) was thwarted by our inability to obtain suitable crystals, the solution behavior of this compound has been comprehensively investigated by Shapiro et al. ${ }^{10,11}$ On the basis of ${ }^{27} \mathrm{Al}$ NMR spectroscopy, these authors concluded that $\mathrm{Cp}_{2}{ }_{2} \mathrm{AlCl}$ dissociates spontaneously into $\mathrm{Cp}^{*}{ }_{2} \mathrm{Al}^{+}$cations and $\mathrm{Cp}_{2}{ }_{2} \mathrm{AlCl}_{2}{ }^{-}$(and possibly other) anions. ${ }^{11}$ More recently, the same group has shown that the related compound $\left(\mathrm{C}_{5} \mathrm{Me}_{5} \mathrm{H}\right)_{2} \mathrm{AlCl}$ exists as a chlorine-bridged dimer with a unique $\eta^{3}, \eta^{1}(\sigma)$-arrangement of the cyclopentadienyl rings. ${ }^{20}$

The methylalane $\mathrm{Cp}^{*}{ }_{2} \mathrm{AlMe}(\mathbf{8})$ was found to have a rare bis $\left(\eta^{2}-\right.$ $\mathrm{Cp}^{*}$ ) structure in which the $\mathrm{Cp}$ * rings are oriented in such a fashion that the $\pi$-systems on the rings are able to donate electron density to the electron-deficient $\mathrm{Al}$ atom. ${ }^{11}$ The crystal system of $\mathbf{8}$ in the original report was in the tetragonal space group $P 42_{1} \mathrm{~m}$. We have isolated a new polymorph of $\mathbf{8}$ that crystallizes in the orthorhombic space group $P 2_{1} 2_{1} 2$ with two half molecules per asymmetric unit. Details of the data collection and refinement are listed in Table 1, a representation of the molecular structure of $\mathbf{8}$ is presented in Fig. 3, and the values of important metrical parameters for the molecules are collated in Table 2. Each molecule is subject to crystallographically-imposed $C_{2}$ symmetry about the Al-Me axis such that one of the $\eta^{2}$-bonded carbon atoms is marginally closer to the aluminum atom. All salient metrical parameters (bond distances, angles, dihedral angles, deviations from least-squares planes, etc.) for this polymorph of $\mathbf{8}$ are virtually indistinguishable from those reported for the tetragonal polymorph, ${ }^{11}$ hence the particular bis $\left(\eta^{2}-\mathrm{Cp}^{*}\right)$ structural arrangement that is adopted appears to be quite favorable for this molecule. The only precedent for the observed $\operatorname{bis}\left(\eta^{2}-\mathrm{Cp}^{*}\right)$ structures is that of the parent methylalane, $\mathrm{Cp}_{2} \mathrm{AlMe}^{21}$
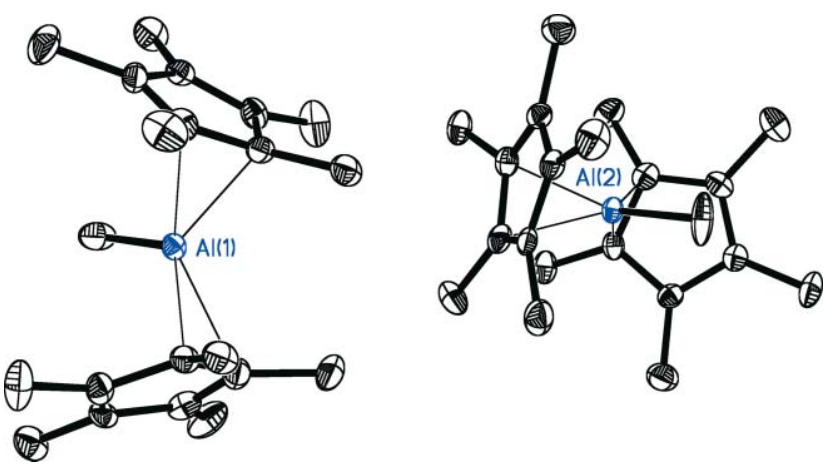

Fig. 3 Thermal ellipsoid plots (30\% probability surface) for $\mathbf{8}$.

Akin to the boron analogues $\mathbf{4}$ and $\mathbf{5}$, but in contrast to the ionic aluminum species 7, both bis(pentamethylcyclopentadienyl)gallium halides $\mathrm{Cp}_{2}{ }_{2} \mathrm{GaX}\left(\mathbf{9}: \mathrm{X}=\mathrm{Cl} ;{ }^{22}\right.$ 10: $\left.\mathrm{X}=\mathrm{Br}\right)$ possess well-defined covalent solid-state structures. Compound 9 was synthesized by Beachley et al. ${ }^{22}$ via the metathetical reaction of two equivalents of $\mathrm{Cp}$ * $\mathrm{Li}$ with $\mathrm{GaCl}_{3}$ and we employed essentially the same method for the preparation of $\mathbf{1 0}$. As expected, the ${ }^{1} \mathrm{H}$ and ${ }^{13} \mathrm{C}$ NMR spectra of $\mathbf{9}$ and $\mathbf{1 0}$ exhibit resonances that are typical of a single type of rapidly-migrating $\mathrm{Cp}^{*}$ ligand. Highresolution mass spectrometric studies confirm the compositions of the parent peaks and the fragmentation patterns observed in the low-resolution positive-ion CI-MS experiments support the structural assignments as evidenced by the prominent daughter ions for $\mathrm{Cp}^{*}{ }_{2} \mathrm{Ga}$ (base peak) and $\mathrm{Cp} * \mathrm{GaX}$.

Bis(pentamethylcyclopentadienyl)gallium bromide is isostructural with $\mathrm{Cp}^{*}{ }_{2} \mathrm{GaCl}^{22}$ Unfortunately, the crystal quality of $\mathbf{1 0}$ was poor but good enough to establish the connectivity (Fig. 4). The molecular structures of $\mathbf{9}^{22}$ and $\mathbf{1 0}$ consist of halide dimers of the form $\mathrm{Cp}^{*}{ }_{2} \mathrm{Ga}\left(\mu^{2}-\mathrm{X}\right)_{2} \mathrm{GaCp}_{2}{ }_{2}$. The asymmetric unit of each structure contains three independent $\mathrm{Cp}^{*}{ }_{2} \mathrm{GaX}$ fragments (one complete dimer and a moiety that is completed by the crystallographic inversion center). In accord with the data found in the Cambridge Structural Database (CSD) ${ }^{23}$ the metrical parameters for the cyclopentadienyl rings are suggestive of localized
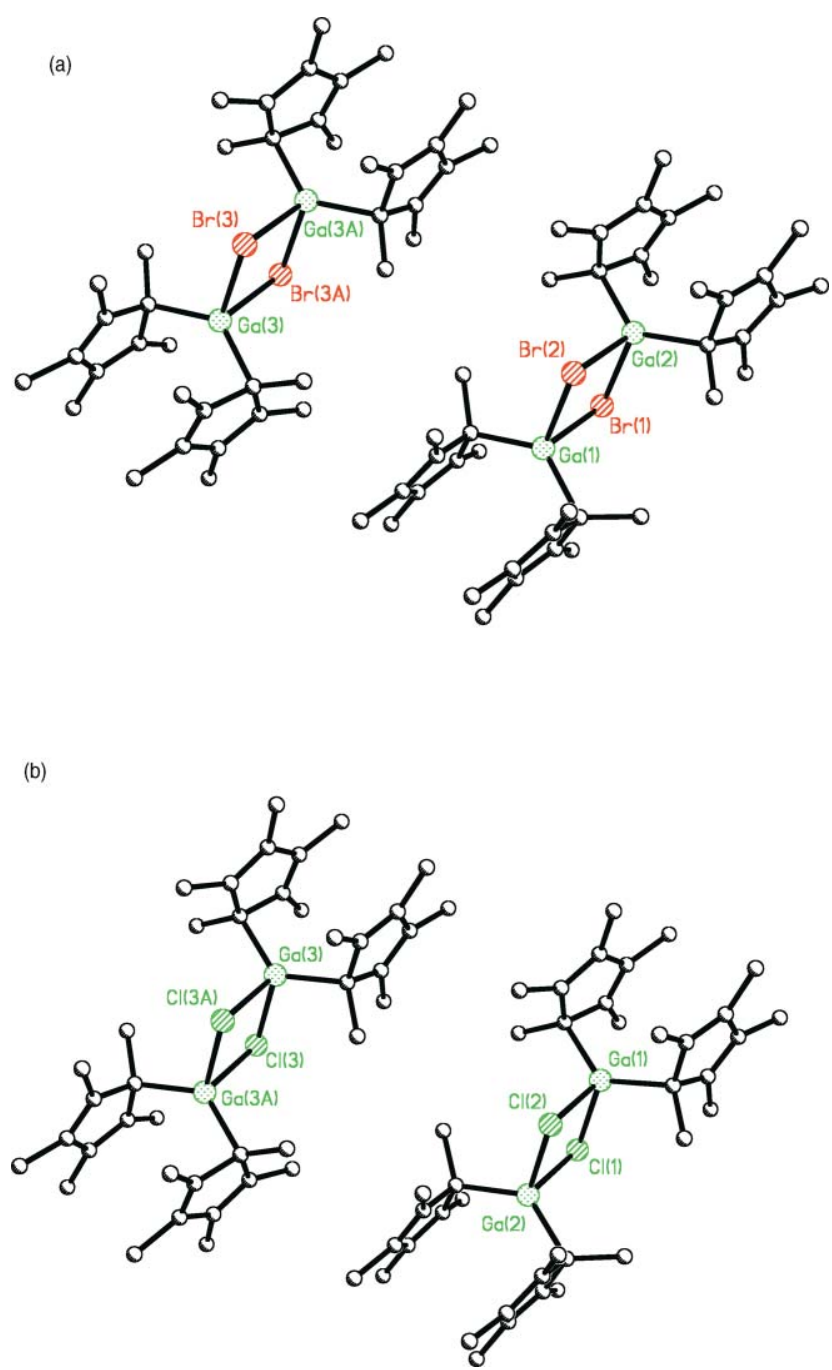

Fig. 4 Connectivity diagram for $\mathbf{1 0}$ (top), illustrating the isostructural relationship with chloride analogue 9 (bottom). ${ }^{22}$ 
diene fragments and indicate that the rings are $\eta^{1}(\sigma)$-bonded to the gallium center in the solid state. However, in contrast to the analogous boron halides, the two $\mathrm{Cp}^{*}$ rings attached to a given Ga center of $\mathbf{9}$ and $\mathbf{1 0}$ are stacked nearly on top of each other. Evidently, the larger ionic radius of $\mathrm{Ga}^{3+}(0.76 \AA)$ vis-àvis that of $\mathrm{B}^{3+}(0.41 \AA)$ permits an adequate separation of the $\pi$-systems of the two rings such that a twisted arrangement is rendered unnecessary. The attempted preparation of $\mathrm{Cp}^{*}{ }_{2} \mathrm{GaMe}$ (11) by treatment of the halogallanes $9^{22}$ and 10 with $\mathrm{MeLi}$ yielded complex mixtures of $\mathrm{Cp}^{*}$-containing products. However, a successful synthesis of $\mathbf{1 1}$ was realized via the metathetical reaction of $\mathrm{GaMeCl}_{2}$ with two equivalents of $\mathrm{Cp} * \mathrm{Li}$ in diethyl ether solution. Block-shaped crystals of $\mathbf{1 1}$ suitable for analysis by single-crystal X-ray diffraction (Table 1) were obtained by cooling a concentrated diethyl ether solution of the gallane overnight. The molecular structure of $\mathbf{1 1}$ is depicted in Fig. 5 and selected metrical parameters are listed in Table 2. Somewhat expectedly, the structure of $\mathbf{1 1}$ is reminiscent of that of the aluminum analogue 8. However, in contrast to the aluminum analogue, only one of the rings of $\mathbf{1 1}$ is bonded in an $\eta^{2}$-fashion while the other ring appears to be better described as being attached in an $\eta^{1}$ manner. Predictably, and in contrast to the halogallanes described above, the metrical parameters of both rings are suggestive of significantly more $\pi$-delocalization in both of the $\mathrm{Cp}^{*}$ rings. As proposed above for the methylborane $\mathbf{6}$ and the methylalane $\mathbf{8}$, the observed ring orientations in $\mathbf{1 1}$ permit efficient overlap of the ring $\pi$-systems with the putatively vacant $4 \mathrm{p}$ orbital on the gallium center. Presumably, such interactions are necessary in the case of $\mathbf{1 1}$ to compensate for the inferior $\pi$-donating/bridging ability of the methyl substituent in $\mathbf{1 1}$ in comparison with those of the halogen substituents in $\mathbf{9}$ and $\mathbf{1 0 .}$

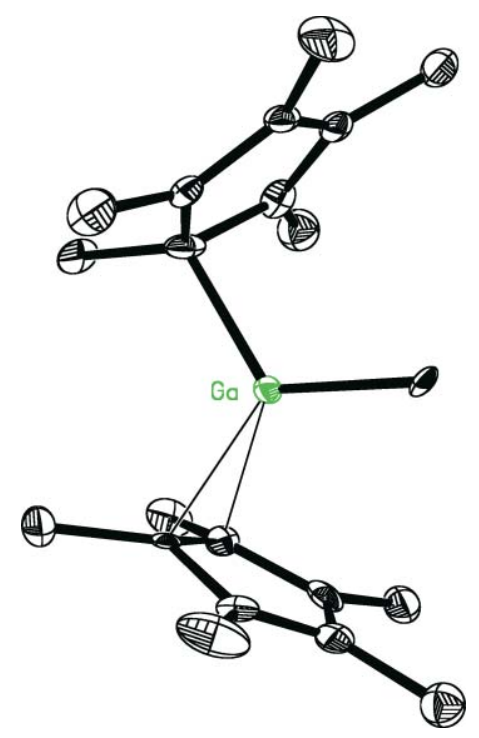

Fig. 5 Thermal ellipsoid plot (30\% probability surface) for $\mathbf{1 1}$

\section{Decamethylmetallocenium salts}

The various metal-dependent similarities and differences between the group 13 pentamethylcyclopentadienyl compounds that were described and discussed above are mirrored in the series of isovalent cations derived from the respective precursors.
Multinuclear NMR experiments indicate that the treatment of haloborane $\mathbf{4}$ (or $\mathbf{5}$ in some cases) with halide-abstraction reagents such as $\mathrm{Li}\left[\mathrm{B}\left(\mathrm{C}_{6} \mathrm{~F}_{5}\right)_{4}\right], \mathrm{AlCl}_{3}$ or $\mathrm{GaCl}_{3}$ produces the decamethylborocenium $\left(\mathbf{1}^{+}\right)$salts $\left[\mathrm{Cp}^{*}{ }_{2} \mathrm{~B}\right][\mathrm{X}], \mathrm{X}=\left[\mathrm{B}\left(\mathrm{C}_{6} \mathrm{~F}_{5}\right)_{4}\right]^{-}$, $\mathrm{AlCl}_{4}{ }^{-}, \mathrm{GaCl}_{4}{ }^{-}$. Similarly, the treatment of methylborane 6 with methanide-abstraction reagents such as $\mathrm{Ga}\left(\mathrm{C}_{6} \mathrm{~F}_{5}\right)_{3}$ also results in the formation of salts of $\mathbf{1}^{+}$. The highly-shielded ${ }^{11} \mathrm{~B}$ NMR chemical shift of approximately $\delta-40 \mathrm{ppm}$ for the decamethylborocenium cation is quite distinctive, retained in both solution and the solid phase, ${ }^{19}$ and thus diagnostic of the formation of this cation. Furthermore, as first noted by Jutzi et al., ${ }^{5}$ and in contrast to most other main group metallocenes, the ${ }^{1} \mathrm{H}$ and ${ }^{13} \mathrm{C}$ NMR spectra of solutions of salts of $\mathbf{1}^{+}$evidence the presence of two distinct $\mathrm{Cp}^{*}$ groups. Under such conditions, one $\mathrm{Cp}^{*}$ substituent appears to be undergoing the typical 1,2-sigmatropic shift behavior while the other ring is apparently locked in a single $\eta^{1}(\sigma)$-bonded form. Comparable behavior has also been observed in solid-state NMR experiments. ${ }^{19}$

Despite the unambiguous multinuclear NMR spectroscopic evidence for the formation of the decamethylborocenium salts discussed above, it only proved possible to characterize one such salt by single-crystal X-ray diffraction (Table 3). Suitable crystals of $\mathbf{1}\left[\mathbf{A l C l}_{4}\right]$ were obtained by slow cooling of a saturated dichloromethane solution to $-20{ }^{\circ} \mathrm{C}$ overnight. The contents of the asymmetric unit of this salt are presented in Fig. 6 and pertinent metrical parameters for the structure are compiled in Table 4. Although two crystallographically-independent cations and anions are present, their metrical parameters are virtually indistinguishable and, in the following text, the data for the second independent molecule are shown in brackets. The most important structural features of each cation are the non-parallel arrangement of the $\mathrm{Cp}^{*}$ rings and the fact that one ring is $\eta^{1}$-bonded while the second ring is attached in a pentahapto fashion. Moreover, the normal of the $\sigma$-bonded ring is canted at an angle of $20.1^{\circ}\left[16.9^{\circ}\right]$ with respect to the plane of the $\eta^{5}$-bonded ring. The hapticities of each ring are readily assigned on the basis of the metrical parameters of each ring. For example, the $\sigma$-bonded rings exhibit average $\mathrm{C}_{i p s o}-\mathrm{C}_{\alpha}$ distances $(1.519 \AA$ [1.521 $\AA$ ] ) that are typical of single bonds whereas the $\mathrm{C}_{\beta}-\mathrm{C}_{\beta}$ distance (1.471(6) $\AA$ [1.467(6) $\left.\AA\right]$ ) and average $\mathrm{C}_{\alpha}-\mathrm{C}_{\beta}$ distances $(1.343 \AA$ [1.344 $\AA$ ] $)$ are characteristic of a conjugated diene fragment. In contrast, the bond distances for the $\eta^{5}$-bonded ring lie between 1.424(5) and 1.431(5) $\AA$ [1.419(5)

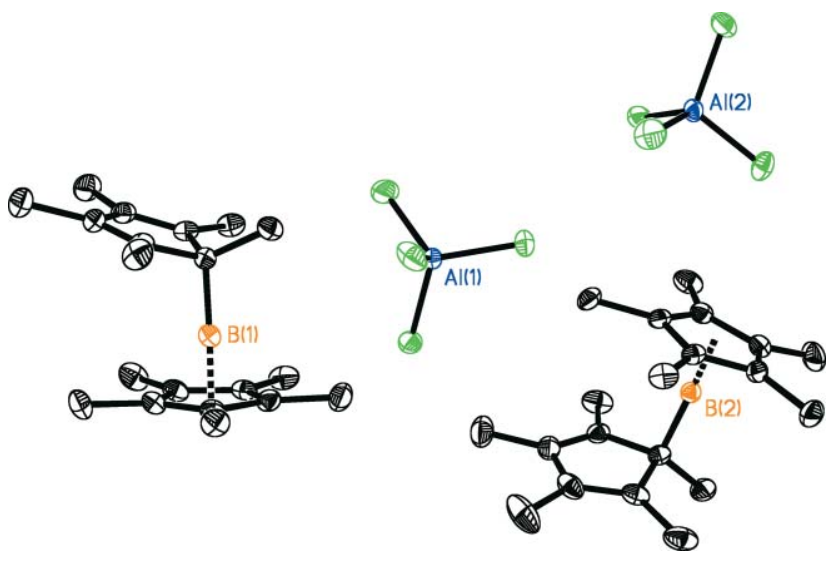

Fig. 6 Thermal ellipsoid plots (30\% probability surface) for $\mathbf{1}\left[\mathbf{A I C l}_{4}\right]$. 
Table 3 Crystallographic data for compounds $\mathbf{1}\left[\mathrm{AICl}_{4}\right], 2\left[\mathrm{AICl}_{4}\right], 3\left[\mathrm{BF}_{4}\right]$ and $3\left[\mathrm{AICl}_{4}\right]$

\begin{tabular}{|c|c|c|c|c|}
\hline \multirow{2}{*}{$\frac{\text { Compound }}{\text { Compound number }}$} & \multirow{2}{*}{$\frac{\left[\mathrm{Cp}_{2}{ }_{2} \mathrm{~B}\right]\left[\mathrm{AlCl}_{4}\right]}{\mathbf{1}\left[\mathrm{AlCl}_{4}\right]}$} & \multirow{2}{*}{$\frac{\left[\mathrm{Cp}_{2}{ }_{2} \mathrm{Al}\right]\left[\mathrm{AlCl}_{4}\right]}{2\left[\mathrm{AlCl}_{4}\right]}$} & \multirow{2}{*}{$\frac{\left[\mathrm{Cp}_{2}{ }_{2} \mathrm{Ga}\right]\left[\mathrm{BF}_{4}\right]}{3\left[\mathbf{B F}_{4}\right]}$} & \multirow{2}{*}{$\frac{\left[\mathrm{Cp}^{*}{ }_{2} \mathrm{Ga}\right]\left[\mathrm{AlCl}_{4}\right]}{3\left[\mathrm{AlCl}_{4}\right]}$} \\
\hline & & & & \\
\hline Empirical formula & $\mathrm{C}_{20} \mathrm{H}_{30} \mathrm{AlBCl}_{4}$ & $\mathrm{C}_{20} \mathrm{H}_{30} \mathrm{Al}_{2} \mathrm{Cl}_{4}$ & $\mathrm{C}_{20} \mathrm{H}_{30} \mathrm{BF}_{4} \mathrm{Ga}$ & $\mathrm{C}_{20} \mathrm{H}_{30} \mathrm{AlCl}_{4} \mathrm{Ga}$ \\
\hline Formula weight & 450.03 & 466.20 & 426.97 & 508.94 \\
\hline Temperature/K & $153(2)$ & $153(2)$ & $133(2)$ & $153(2)$ \\
\hline Wavelength/Å & 0.71073 & 0.71073 & 0.71073 & 0.71073 \\
\hline Crystal system & Monoclinic & Triclinic & Orthorhombic & Monoclinic \\
\hline Space group & $P 2_{1} / n$ & $P-1$ & Pbcn & $P 2_{1} / c$ \\
\hline \multicolumn{5}{|l|}{ Unit cell dimensions } \\
\hline$a / \AA ̊$ & $17.133(3)$ & $7.75480(10)$ & $11.9721(4)$ & $13.3800(7)$ \\
\hline$b / \AA$ & $13.611(3)$ & $17.3747(3)$ & $16.4808(4)$ & $11.5016(7)$ \\
\hline$c / \AA ̊$ & $20.493(4)$ & $18.0806(4)$ & $20.4486(7)$ & $15.8623(8)$ \\
\hline$a /^{\circ}$ & 90 & $85.7100(7)$ & 90 & 90 \\
\hline$\beta /^{\circ}$ & $90.30(3)$ & $83.6011(8)$ & 90 & $99.449(3)$ \\
\hline$\gamma /{ }^{\circ}$ & 90 & $84.7879(7)$ & 90 & 90 \\
\hline Volume $/ \AA^{3}$ & $4778.8(16)$ & $2405.79(7)$ & $4034.7(2)$ & $2408.0(2)$ \\
\hline$Z$ & 8 & 4 & 8 & 4 \\
\hline Calculated density $/ \mathrm{g} \mathrm{cm}^{-3}$ & 1.251 & 1.287 & 1.406 & 1.404 \\
\hline Absorption coefficient $/ \mathrm{mm}^{-1}$ & 0.535 & 0.568 & 1.400 & 1.626 \\
\hline$F(000)$ & 1888 & 976 & 1776 & 1048 \\
\hline Crystal size (mm) & $0.5 \times 0.5 \times 0.5$ & $0.4 \times 0.4 \times 0.3$ & $0.20 \times 0.20 \times 0.05$ & $0.5 \times 0.5 \times 0.5$ \\
\hline Theta range for data collection $/^{\circ}$ & 2.98 to 27.49 & 2.99 to 25.06 & 3.16 to 27.47 & 3.15 to 27.46 \\
\hline \multirow[t]{3}{*}{ Limiting indices } & $-22 \leq h \leq 22$ & $-9 \leq h \leq 9$ & $-13 \leq h \leq 15$ & $-17 \leq h \leq 17$ \\
\hline & $-17 \leq k \leq 17$ & $-18 \leq k \leq 20$ & $-21 \leq k \leq 19$ & $-13 \leq k \leq 14$ \\
\hline & $-26 \leq l \leq 26$ & $-21 \leq l \leq 20$ & $-26 \leq l \leq 24$ & $-20 \leq l \leq 17$ \\
\hline Reflections collected/unique & $1971 \overline{8} / 10898$ & $32448 / 8499$ & $2491 \overline{4} / 4 \overline{539}$ & $2278 \overline{8} / 5 \overline{4} 70$ \\
\hline$R_{\text {int }}$ & 0.0376 & 0.0411 & 0.0736 & 0.0881 \\
\hline Data/restraints/parameters & $10898 / 0 / 469$ & $8499 / 0 / 489$ & $4539 / 0 / 246$ & $5470 / 0 / 245$ \\
\hline Goodness-of-fit on $F^{2}$ & 1.038 & 1.013 & 1.019 & 1.025 \\
\hline Final $R$ indices $[I>2 \sigma(I)]$ & $\begin{array}{l}R_{1}=0.0709 \\
w R_{2}=0.1889\end{array}$ & $\begin{array}{l}R_{1}=0.0465 \\
w R_{2}=0.1097\end{array}$ & $\begin{array}{l}R_{1}=0.0474 \\
w R_{2}=0.0841\end{array}$ & $\begin{array}{l}R_{1}=0.0499 \\
w R_{2}=0.0872\end{array}$ \\
\hline$R$ indices (all data) & $\begin{array}{l}R_{1}=0.1122 \\
w R_{2}=0.2117\end{array}$ & $\begin{array}{l}R_{1}=0.0703 \\
w R_{2}=0.1219\end{array}$ & $\begin{array}{l}R_{1}=0.0946 \\
w R_{2}=0.0968\end{array}$ & $\begin{array}{l}R_{1}=0.1024 \\
w R_{2}=0.1032\end{array}$ \\
\hline Largest diff. peak and hole/e $\AA^{-3}$ & 0.825 and -0.502 & 0.970 and -0.754 & 0.733 and -0.523 & 0.343 and -0.448 \\
\hline
\end{tabular}

Refinement method: full-matrix least-squares on $F^{2}$ for all structures.

and 1.430(5) $\AA$ ] and are thus indicative of a completely delocalized $\pi$-system. The angle subtended at boron between the centroid of the $\eta^{5}$-bonded $\mathrm{Cp}^{*}$ ring and the ipso carbon on the $\sigma$-bonded ring of $178.0(4)^{\circ}\left[177.1(4)^{\circ}\right]$ indicates an essentially linear arrangement about the boron center. Since there are no unusually close contacts between the tetrachloroaluminate anions and the borocenium cations, the structural features of the cations are identical to those that have been predicted computationally. ${ }^{6,24,25}$

The $\eta^{5}, \sigma$-bonding arrangement observed for the decamethylborocenium cations in $\mathbf{1}\left[\mathbf{A} \mathbf{A} \mathbf{C l}_{\mathbf{4}}\right]$ is most simply understood on the basis that such an arrangement provides for a total of eight valence electrons around the boron center. Given the relatively large electronegativity of boron (in comparison with other main group elements) the nature of the bonding in this molecule is probably best-described as being primarily covalent in nature..$^{25}$ On the other hand, the observed $\eta^{5}, \sigma$-bonding arrangement is one that minimizes the repulsion between the $\pi$-systems on the cyclopentadienyl rings. This is a particularly important consideration for a system that features a cationic center as small as $\mathrm{B}^{3+}$. The subtle interplay between electronic and steric effects in determining the structure adopted by a metallocene is much more obvious in the isoelectronic analogues that contain the larger and less electronegative $\mathrm{Be}^{+2}$ center. These molecules exhibit "slipped sandwich" $\eta^{5}, \eta^{1}$-rings, $\eta^{5}, \sigma$-rings or $\eta^{5}, \eta^{5}$-rings depending on the cyclopentadienyl ring substituents. ${ }^{18,26,27}$
The research groups of Bochmann and Shapiro have demonstrated that $\mathrm{B}\left(\mathrm{C}_{6} \mathrm{~F}_{5}\right)_{3}$-promoted methanide abstraction from precursors of the type $\mathrm{Cp}_{2}^{\prime} \mathrm{AlMe}\left(\mathrm{Cp}^{\prime}=\mathrm{Cp}^{4}, \mathrm{Cp}^{* 11}\right)$ represents a viable synthetic route to aluminocenium salts. Alternative synthetic routes to salts of $\left[\mathrm{Cp}^{*}{ }_{2} \mathrm{Al}\right]^{+}\left(\mathbf{2}^{+}\right)$have been introduced by Schnöckel et al. and include the disproportionation of $\mathrm{Cp} * \mathrm{Al}$ by reagents such as $\mathrm{AlCl}_{3}{ }^{7} \mathrm{Li}\left(\mathrm{C}_{5} \mathrm{Bz}_{5}\right)^{8}$ and $\mathrm{BiI}_{3},{ }^{9}$ or by treatment of $\mathrm{AlCl}$ with $\mathrm{Cp}^{*}{ }_{2} \mathrm{Mg} .{ }^{13}$ In our group, we found that the tetrachloroaluminate salt $\mathbf{2}\left[\mathbf{A l C l}_{4}\right]$ can be conveniently synthesized in a similar fashion to that of the boron congener. ${ }^{12}$ Akin to the decamethylborocenium salts, decamethylaluminocenium cations can be unambiguously identified on the basis of a distinctive ${ }^{27} \mathrm{Al}$ NMR resonance at $\delta-100 \mathrm{ppm}$. We have reported the X-ray crystal structure of $2\left[\mathbf{A l C l}_{4}\right]$ previously as part of an extensive solid-state NMR study. ${ }^{12}$ However, in the interest of completeness, we now present an amplified discussion along with a tabulation of metrical parameters (Table 4).

As in the case of the analogous boron salt, the asymmetric unit of $\mathbf{2}\left[\mathbf{A} \mathbf{I C l}_{\mathbf{4}}\right]$ features two crystallographically-independent, yet virtually indistinguishable, pairs of cations (in the following text, the data for the second independent molecule are placed in brackets). The most obvious structural feature of the decamethylaluminocenium cations is the ferrocene-like $\eta^{5}, \eta^{5}$-arrangement of the cyclopentadienyl rings (Fig. 7). The $\mathrm{C}-\mathrm{C}$ distances in the rings range from 1.430 (4) to $1.439(4) \AA[1.428(4)$ to $1.440(4) \AA]$ 
Table 4 Bond distances $(\AA)$ and angles $\left(^{\circ}\right)$ for compounds $\mathbf{1}\left[\mathbf{A I C l}_{4}\right], \mathbf{2}\left[\mathbf{A l C l}_{4}\right], \mathbf{3}\left[\mathbf{B F}_{4}\right]$ and $\mathbf{3}\left[\mathbf{A l C l}_{4}\right]$

\begin{tabular}{|c|c|c|c|c|c|c|}
\hline Compound & {$\left[\mathrm{Cp}_{2}{ }_{2} \mathrm{~B}\right]\left[\mathrm{AlCl}_{4}\right]$} & Compound & {$\left[\mathrm{Cp}_{2}{ }_{2} \mathrm{Al}\right]\left[\mathrm{AlCl}_{4}\right]$} & Compound & {$\left[\mathrm{Cp}^{*}{ }_{2} \mathrm{Ga}\right]\left[\mathrm{BF}_{4}\right]$} & {$\left[\mathrm{Cp}_{2}{ }_{2} \mathrm{Ga}\right]\left[\mathrm{AlCl}_{4}\right]$} \\
\hline \multirow{2}{*}{ Compound number } & Molecule $1^{a}$ & & Molecule $1^{a}$ & & & \\
\hline & & & & $\mathrm{Ga}-\mathrm{X}$ & $2.1847(18)$ & $3.000(1)$ \\
\hline \multirow[t]{2}{*}{$\mathrm{C}_{i p s o}-\mathrm{B}-\mathrm{Cp}^{*}{ }_{\text {cent }}$} & $178.0(4)$ & $\mathrm{Cp}^{*}{ }_{\text {cent }}-\mathrm{Al}-\mathrm{Cp}^{*}{ }_{\text {cent }}$ & $179.85(5)$ & $\mathrm{Ga}-\mathrm{X}$ & $2.1740(17)$ & $3.160(1)$ \\
\hline & & & & $\mathrm{E}-\mathrm{X}_{\text {bridging }}$ & $1.420(3)$ & $2.1481(13)$ \\
\hline Ring 1 & & Ring 1 & & $\mathrm{E}-\mathrm{X}_{\text {bridging }}$ & $1.421(3)$ & $2.1623(13)$ \\
\hline $\mathrm{C}_{i p s o}-\mathrm{C}_{\alpha}$ & $1.514(5)$ & $\mathrm{C}-\mathrm{C}$ & $1.431(4)$ & terminal & & \\
\hline $\mathrm{C}_{\alpha}-\mathrm{C}_{\beta}$ & $1.344(5)$ & $\mathrm{C}-\mathrm{C}$ & $1.431(4)$ & $\mathrm{C}_{i p s o}-\mathrm{Ga}-\mathrm{Cp}^{*}{ }_{\text {cent }}$ & $123.25(7)$ & $140.52(9)$ \\
\hline $\mathrm{C}_{\alpha}-\mathrm{C}_{\beta}$ & $1.341(5)$ & $\mathrm{C}-\mathrm{C}$ & $1.434(4)$ & & & \\
\hline \multirow[t]{2}{*}{$\mathrm{C}_{\beta}-\mathrm{C}_{\beta}$} & $1.471(6)$ & $\mathrm{C}-\mathrm{C}$ & $1.431(4)$ & Ring 1 & & \\
\hline & & & & $\mathrm{Ga}-\mathrm{C}_{i p s o}$ & $1.972(3)$ & $1.996(3)$ \\
\hline Ring 2 & & Ring 2 & & $\mathrm{C}_{i p s o}-\mathrm{C}_{\alpha}$ & $1.509(4)$ & $1.506(4)$ \\
\hline $\mathrm{B}-\mathrm{Cp}^{*}{ }_{\mathrm{cent}}$ & $1.289(4)$ & $\mathrm{Al}-\mathrm{Cp}{ }^{*}{ }_{\text {cent }}$ & $1.770(1)$ & $\mathrm{C}_{i p s o}-\mathrm{C}_{\alpha}$ & $1.506(4)$ & $1.500(4)$ \\
\hline \multirow[t]{2}{*}{$\mathrm{C}-\mathrm{C}$} & $1.425(6)$ & $\mathrm{C}-\mathrm{C}$ & $1.439(4)$ & Ring 2 & & \\
\hline & & & & $\mathrm{Ga}-\mathrm{Cp}_{\text {cent }}^{*}$ & $2.134(1)$ & $1.904(1)$ \\
\hline $\mathrm{Al}-\mathrm{Cl}$ & $2.1253(15)$ & $\mathrm{Al}-\mathrm{Cl}$ & $2.1219(15)$ & $\mathrm{Ga}-\mathrm{C}_{i p s o}$ & $2.002(3)$ & $2.098(3)$ \\
\hline $\mathrm{Al}-\mathrm{Cl}$ & $2.1276(17)$ & $\mathrm{Al}-\mathrm{Cl}$ & $2.1331(12)$ & $\mathrm{Ga}-\mathrm{C}_{\alpha}$ & $2.354(4)$ & $2.193(4)$ \\
\hline $\mathrm{Al}-\mathrm{Cl}$ & $2.1489(19)$ & $\mathrm{Al}-\mathrm{Cl}$ & $2.1309(12)$ & $\mathrm{Ga}-\mathrm{C}_{\alpha}$ & $2.352(3)$ & $2.219(3)$ \\
\hline \multirow[t]{7}{*}{$\mathrm{Al}-\mathrm{Cl}$} & $2.128(2)$ & $\mathrm{Al}-\mathrm{Cl}$ & $2.1393(11)$ & $\mathrm{Ga}-\mathrm{C}_{\beta}$ & $2.737(4)$ & $2.385(3)$ \\
\hline & & & & $\mathrm{Ga}-\mathrm{C}_{\beta}$ & $2.743(3)$ & $2.395(3)$ \\
\hline & & & & $\mathrm{C}_{i p s o}-\mathrm{C}_{a}$ & $1.459(4)$ & $1.451(4)$ \\
\hline & & & & $\mathrm{C}_{i p s o}-\mathrm{C}_{\alpha}$ & $1.467(4)$ & $1.447(5)$ \\
\hline & & & & $\mathrm{C}_{\alpha}-\mathrm{C}_{\beta}$ & $1.386(5)$ & $1.430(5)$ \\
\hline & & & & $\mathrm{C}_{\alpha}-\mathrm{C}_{\beta}$ & $1.386(4)$ & $1.420(4)$ \\
\hline & & & & $\mathrm{C}_{\beta}-\mathrm{C}_{\beta}$ & $1.417(5)$ & $1.417(4)$ \\
\hline
\end{tabular}

${ }^{a}$ See ESI for molecule 2.

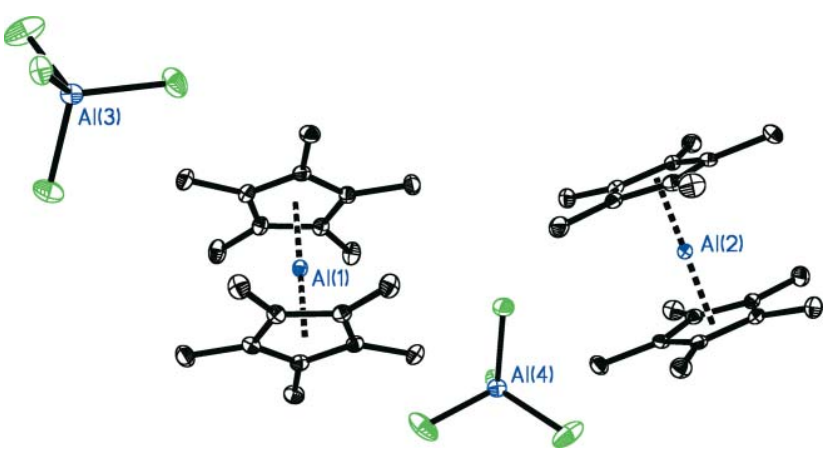

Fig. 7 Thermal ellipsoid plots (30\% probability surface) for $\mathbf{2}\left[\mathbf{A I C l}_{4}\right]$.

and are thus indicative of the complete delocalization of the ring $\pi$-bonding. The $\mathrm{Cp}^{*}$ ring centroids $(\mathrm{X})$ are located at distances of 1.767(1) and 1.770(1) $\AA$ [1.774(1) and 1.772(1) $\AA$ ] from the aluminum atom with an $\mathrm{X}-\mathrm{Al}-\mathrm{X}$ angle of $179.85(5)^{\circ}\left[179.48(5)^{\circ}\right]$. Moreover, the $\mathrm{Cp}^{*}$ rings on a given cation are almost perfectly staggered with respect to each other, hence each cation possesses almost ideal $D_{5 \mathrm{~d}}$ symmetry even in the absence of any constraints imposed by the space group. The cationic structure is virtually identical to those found for other decamethylaluminocenium salts and is therefore not dependent on the nature of the counter anion.

The adoption of the $\eta^{5}, \eta^{5}$-bonding arrangement, which is more reminiscent of the group 2 metallocenes (and the transition metal analogues), is probably best rationalized in terms of the relatively low electronegativity of aluminum and the larger size of aluminum in comparison with the second-row elements. The electropositive nature of aluminum increases the ionicity of the metal-ring bonding and thus favors higher hapticities for the metal-ring interactions. ${ }^{25}$ It is also noteworthy that the predominantly ionic nature of the bonding in decamethylaluminocene renders the "hypervalent" electron count of 12 around the aluminum center irrelevant. Given that $\mathrm{Be}$, which is slightly less electronegative than $\mathrm{Al}\left(\chi_{\mathrm{Be}}=1.576 ; \chi_{\mathrm{Al}}=1.613\right.$ on the Allen scale $\left.{ }^{28}\right)$, exhibits the variety of structures described above, the adoption of an essentially perfect $D_{5 \mathrm{~d}}$ structure by $\mathbf{2}^{+}$is almost certainly a consequence of the larger size of $\mathrm{Al}^{3+}$ ion $\left(r \mathrm{Be}^{2+}=0.31 \AA ; \mathrm{Al}^{3+}=0.50 \AA\right.$ using Pauling's values from http://www.webelements.com). The larger distance between the $\pi$-electron clouds on the cyclopentadienyl rings in the aluminocenium cation obviates the ring "slippage" or the $\pi$-localization that is adopted to reduce the electron cloud repulsion in the isovalent beryllocenes.

In contrast to the relatively straightforward synthetic approaches used to obtain the lighter analogues, the synthesis of decamethylgallocenium salts turned out to be considerably more challenging. For example, whereas chloride anion abstraction represents a viable method for the synthesis of tetrachloroaluminate salts of $\mathbf{1}^{+}$and $\mathbf{2}^{+}$, the reaction of 9 with $\mathrm{Al}_{2} \mathrm{Cl}_{6}$ in dichloromethane solution resulted in the formation of mixtures of several products that originated from the transfer of $\mathrm{Cp}^{*}$ and $\mathrm{Cl}$ substituents between the group 13 atoms. An alternative synthetic approach was thus called for and, given the availability of $\mathrm{Cp}_{3}{ }_{3} \mathrm{Ga} \mathrm{12}{ }^{29}$ 
the protolytic removal of $\mathrm{Cp}^{*} \mathrm{H}$ from $\mathbf{1 2}$ appeared to be an attractive option. Indeed, the treatment of $\mathbf{1 2}$ with $\mathrm{H}\left[\mathrm{BF}_{4}\right]$ in dichoromethane solution resulted in $\mathrm{Cp}^{*} \mathrm{H}$ elimination and the production of the salt $3\left[\mathbf{B F}_{4}\right]$ in high yield as evidenced by ${ }^{1} \mathrm{H}$, ${ }^{13} \mathrm{C},{ }^{11} \mathrm{~B}$ and ${ }^{19} \mathrm{~F}$ NMR experiments. After removal of all of the volatile components under reduced pressure, recrystallization of the resultant pale yellow powder from dichloromethane solution afforded pale yellow plate-like crystals of $3\left[\mathbf{B F}_{\mathbf{4}}\right]$ suitable for analysis by single-crystal X-ray diffraction (Table 3 ).

The salt $\mathbf{3}\left[\mathbf{B F}_{4}\right]$ crystallizes in the space group Pbcn with a complete cation and two half anions located in the asymmetric unit. Upon inclusion of the atoms related by the crystallographic $C_{2}$ axis passing through the boron atoms, the anion-linked dimeric structure of $3\left[\mathbf{B F}_{4}\right]$ is apparent, as illustrated in Fig. 8; salient metrical parameters for this salt are presented in Table 4.

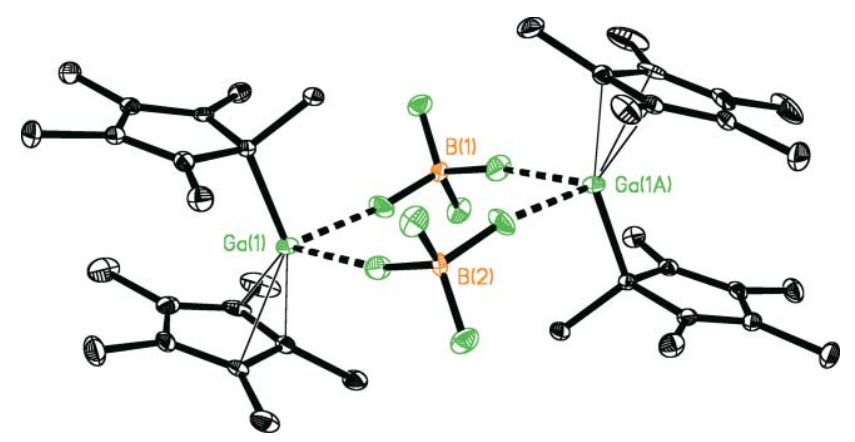

Fig. 8 Thermal ellipsoid plots (30\% probability surface) for $\mathbf{3}\left[\mathbf{B F}_{4}\right]$.

Several important features of the structure of $\mathbf{3}\left[\mathbf{B F}_{\mathbf{4}}\right]$ differentiate it from those of the lighter homologues. The most obvious distinction is the existence of close contacts between the anions and the cations. The Ga $\cdots F$ separations of 2.1847(18) and 2.1740 (17) $\AA$ are conspicuously short and, although they exceed the range of 1.755 to $1.936 \AA$ reported for covalent $\mathrm{Ga}-\mathrm{F}$ bonds reported in the CSD, they fall well within the sum of the van der Waals radii for $\mathrm{Ga}(1.87 \AA)$ and $\mathrm{F}(1.47 \AA)$. These strong anioncation interactions are also clearly manifested in the distortions away from the ideal tetrahedral geometry of the tetrafluoroborate anions. Thus, whereas the B-F distances for the terminal fluorine atoms are 1.357(3) and 1.358(3) $\AA$, the distances for the bridging fluorine atoms are considerably longer (1.420(3) and 1.421(3) ̊).

Several gross and fine structural features of the decamethylgallocenium fragment in $3\left[\mathrm{BF}_{4}\right]$ are also distinct from those of its lighter congeners. The metrical parameters suggest that one ring is attached to the $\mathrm{Ga}$ center in a $\sigma$-bonded fashion as evidenced by the $\mathrm{Ga}-\mathrm{C}_{i p s o}-\mathrm{Me}$ angle of $109.4(2)^{\circ}$. The localized diene-like pattern of $\mathrm{C}-\mathrm{C}$ distances within the ring $\left(\mathrm{C}_{i p s o}-\mathrm{C}_{\alpha}: 1.509(4)\right.$ and $1.506(4) \AA ; C_{\alpha}-C_{\beta}: 1.350(4)$ and $\left.1.348(4) \AA ; C_{\beta}-C_{\beta}: 1.470(4) \AA\right)$ is also consistent with this interpretation. The other $\mathrm{Cp}^{*}$ ring is best described as being bonded to the gallium center in a $\eta^{3}$ manner. The $\mathrm{C}-\mathrm{C}$ distances within the ring $\left(\mathrm{C}_{i p s o}-\mathrm{C}_{\alpha}: 1.459(4)\right.$ and 1.467(4) $\AA$; $\mathrm{C}_{\alpha}-\mathrm{C}_{\beta}: ; 1.386(5)$ and 1.386(4) $\AA ; \mathrm{C}_{\beta}-\mathrm{C}_{\beta}: 1.417(5) \AA$ ) indicate the presence of a considerably more delocalized $\pi$-system than that in the $\sigma$-bonded ring. Furthermore, the distances between the gallium atom and the carbon atoms in the ring show three relatively short contacts $\left(\mathrm{Ga}-\mathrm{C}_{i p s o}: 2.002(3) \AA ; \mathrm{Ga}-\mathrm{C}_{\alpha}: 2.354(4)\right.$ and $2.352(3) \AA)$ and two significantly longer contacts $\left(\mathrm{Ga}-\mathrm{C}_{\beta}\right.$ : 2.737(4) and 2.743(3) $\AA$ ). The arrangement of the rings on the cation in $\mathbf{3}\left[\mathbf{B F}_{\mathbf{4}}\right]$ is also unique in that, despite their different hapticities, the rings are virtually parallel to each other.

Because the close contacts between the tetrafluoroborate fluorine atoms and the gallium cation in $\mathbf{3}\left[\mathbf{B F}_{4}\right]$ appear to distort the structure of both the cation and the anion from ideality, ${ }^{14,25}$ it was of interest to synthesize a decamethylgallocenium salt containing a less coordinating counter anion. Given the success of the $\mathrm{Cp}^{*}$ protonolysis methodology outlined above, we decided to attempt acidolysis of the $\mathrm{Cp}^{*}$ ring with a Lewis acid. Accordingly, equimolar quantities of $\mathbf{1 2}$ and $\mathrm{AlCl}_{3}$ in dichloromethane solution were stirred until the aluminum chloride was completely dissolved. The resultant bright yellow solution was concentrated under reduced pressure and stored in a freezer; colorless needle-shaped crystals were deposited after $24 \mathrm{~h}$ and bright yellow block-shaped crystals were obtained after $7 \mathrm{~d}$. The colorless crystalline material, which is the major product, was identified as $\left(\mathrm{Cp}^{*}\right)_{2} \mathrm{GaCl}(\mathbf{9})$ on the basis of NMR, MS, and X-ray crystallographic data. The formation of this product is attributable to the simple $\mathrm{Cl}$ for $\mathrm{Cp}$ * ligand exchange on the starting gallane. The bright yellow crystalline minor product was shown to be the decamethylgallocenium salt $\mathbf{3}\left[\mathbf{A l C l}_{\mathbf{4}}\right]$ on the basis of a single-crystal X-ray diffraction study (Table 3 ).

The salt $3\left[\mathbf{A l C l}_{4}\right]$ crystallizes in the space group $P 2_{1} / \mathrm{c}$ with one complete cation and one complete anion in the asymmetric unit, as illustrated in Fig. 9. Selected metrical parameters for $\mathbf{3}\left[\mathbf{A I C l}_{4}\right]$ are listed in Table 4 . While relatively close contacts are evident between the cation and the anion, the $\mathrm{Ga} \cdots \mathrm{Cl}$ distances of $3.000(1)$ and 3.160(1) $\AA$ fall considerably outside the range of approximately $2.1-2.3 \AA$ for $\mathrm{Ga}-\mathrm{Cl}$ covalent bonds reported in the CSD. The consequences of these modest cation-anion interactions on the other structural features of the tetrachloroaluminate anion are considerably less dramatic than those observed in the case of $3\left[\mathbf{B F}_{4}\right]$. For example, the $\mathrm{Al}-\mathrm{Cl}$ distances (2.1481(13) and 2.1623(13) A) for the chlorine atoms that make the contacts with the Ga cation are only slightly longer than those of the terminal chlorine atoms (2.1190(13) and 2.1079(13)), and all of the distances fall within the range of bond lengths reported for tetrachloroaluminate anions in the CSD.

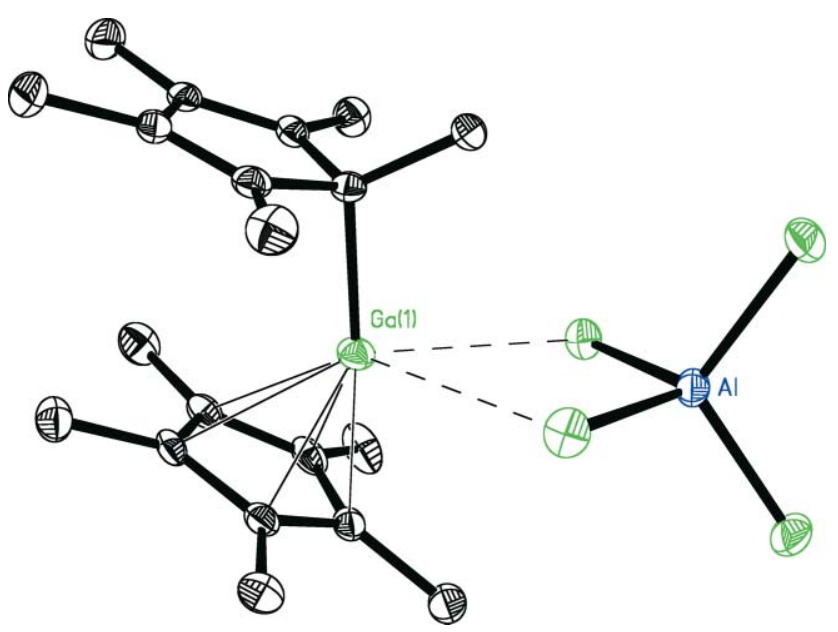

Fig. 9 Thermal ellipsoid plots (30\% probability surface) of $\mathbf{3}\left[\mathbf{A I C l}_{\mathbf{4}}\right]$.

The structure of the cation in $\mathbf{3}\left[\mathbf{A} \mathbf{I C l} \mathbf{C}_{4}\right]$ is best described as containing $\sigma$ - and $\eta^{5}$-bonded $\mathrm{Cp}^{*}$ rings. While, the $\mathrm{Ga}-\mathrm{C}_{i p s o}-\mathrm{Me}$ angle of $114.5(2)^{\circ}$ to the $\sigma$-bonded ring is somewhat obtuse, the 
pattern of $\mathrm{C}-\mathrm{C}$ distances $\left(\mathrm{C}_{i p s o}-\mathrm{C}_{\alpha}: 1.500(4)\right.$ and 1.506(4) $\AA ; \mathrm{C}_{\alpha}-$ $\mathrm{C}_{\beta}: 1.344(4)$ and 1.351(4) $\left.\AA ; \mathrm{C}_{\beta}-\mathrm{C}_{\beta}: 1.475(4) \AA\right)$ in the $\mathrm{Cp}^{*}$ ring is, again, indicative of a localized diene-like bonding arrangement. In contrast, the C-C distances $(1.417(4)-1.451(4) \AA)$ in the $\pi$ bonded ring suggest a considerably more delocalized $\pi$-system. The $\mathrm{Ga}-\mathrm{C}$ distances to the $\pi$-bonded ring exhibit a much smaller range (2.193(4)-2.395(3) $\AA$ ) than those in $\mathbf{3}\left[\mathbf{B F}_{\mathbf{4}}\right]$ and, although the arrangement is not perfectly symmetrical, the description of the molecule as being bonded in an $\eta^{5}$ manner appears to be more appropriate than an $\eta^{3}$ description.

The $\sigma, \eta^{3 / 5}$ bonding arrangement adopted by $\mathbf{3}^{+}$is in obvious contrast to the $\eta^{5}, \eta^{5}$-structure exhibited by the aluminum analogue $\mathbf{2}^{+}$and resembles the $\sigma, \eta^{5}$-structure of the boron congener $\mathbf{1}$ much more closely. Since $\mathrm{Al}$ and $\mathrm{Ga}$ are very similar in size $\left(r \mathrm{Al}^{+3}=\right.$ $0.50 \AA ; r \mathrm{Ga}^{+3}=0.62 \AA$ ), the reason for the adoption of the different structures is clearly not primarily a consequence of steric interactions. The most plausible explanation for the observed structural preferences lies in the different electronegativities of the elements $\left(\chi_{\mathrm{B}}=2.051 ; \chi_{\mathrm{Al}}=1.613 ; \chi_{\mathrm{Ga}}=1.756\right)$. As suggested above, the more electropositive nature of aluminum favors the primarily ionic $\eta^{5}, \eta^{5}$-structure and the more electronegative boron center favors the more covalent eight-electron $\sigma, \eta^{5}$ alternative. It would appear that the electronegativity of gallium is sufficient to favor the more covalent alternative. However, the larger size of gallium allows for the possibility of inter-ionic interactions that distort the structure from ideality.

In light of the above, it should be noted that the arrangement of the two $\mathrm{Cp}^{*}$ substituents is almost identical in the structures of both $\mathbf{3}\left[\mathbf{B F}{ }_{4}\right]$ and $\mathbf{3}\left[\mathbf{A} \mathbf{I C l}_{\mathbf{4}}\right]$, as illustrated in Fig. 10, and the major difference between the cations appears to be the magnitude of the "slippage" of the gallium atom from the centers of stacked $\mathrm{Cp}^{*}$ rings. In the tetrafluoroborate salt, the cation is translated $0.807 \AA$ from the normal to the ring centroid of the $\pi$-bonded ring whereas the comparable translation in the tetrachloroaluminate salt is only $0.311 \AA$. Given that the amount of "slippage" is undoubtedly related to the coordinating ability of the counter anion, it appears that the isolation of an ideal, non-distorted $\eta^{1}, \eta^{5}$ -

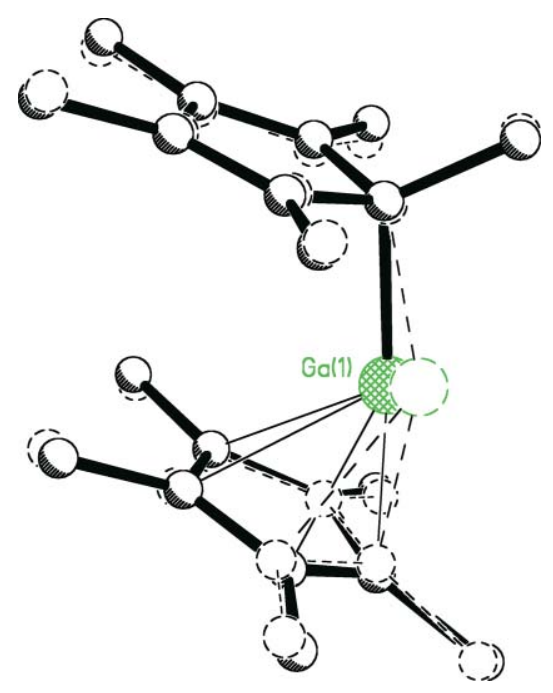

Fig. 10 Overlay of the structures of the decamethylgallocenium cations in $\mathbf{3}\left[\mathbf{A I C l}_{4}\right]$ (solid lines) and $\mathbf{3}\left[\mathbf{B F}_{4}\right]$ (dashed lines). bonded gallocenium cation would require the presence of a truly non-coordinating anion.

Given the foregoing, it was of interest to synthesize a gallocenium salt containing a less coordinating counter anion. The attempted metathetical reactions of $\mathbf{9}$ or $\mathbf{1 0}$ with $\mathrm{Li}\left[\mathrm{B}\left(\mathrm{C}_{6} \mathrm{~F}_{5}\right)_{4}\right]$ resulted in mixtures of products from which it was not possible to isolate any gallocenium salts. Accordingly, the methanide abstraction methodology ${ }^{11}$ was investigated. The treatment of 11 with $\mathrm{B}\left(\mathrm{C}_{6} \mathrm{~F}_{5}\right)_{3}$ in $\mathrm{CH}_{2} \mathrm{Cl}_{2}$ solution produced a yellow solution for which multinuclear $\left({ }^{1} \mathrm{H},{ }^{11} \mathrm{~B},{ }^{13} \mathrm{C}\right.$ and $\left.{ }^{19} \mathrm{~F}\right) \mathrm{NMR}$ experiments exhibit signals that are indicative of the formation of the salt $3\left[\mathbf{M e B}\left(\mathbf{C}_{6} \mathbf{F}_{5}\right)_{3}\right]$. Removal of all volatile components from the reaction mixture produced a pale yellow solid that was recrystallized from $\mathrm{CH}_{2} \mathrm{Cl}_{2}$ to yield a colorless crystalline material that was characterized as the neutral perfluoroarylgallane $\mathrm{Cp}_{2}{ }_{2} \mathrm{Ga}\left(\mathrm{C}_{6} \mathrm{~F}_{5}\right)(\mathbf{1 3})$. This neutral gallane is apparently the product of the "back-transfer" of a pentafluorophenyl substituent from the $\left[\mathrm{MeB}\left(\mathrm{C}_{6} \mathrm{~F}_{5}\right)_{3}\right]^{-}$anion to the gallium cation. Comparable products have been observed previously ${ }^{30-32}$ for other salts composed of group 13 cations and $\left[\mathrm{MeB}\left(\mathrm{C}_{6} \mathrm{~F}_{5}\right)_{3}\right]$ anions. Interestingly, if the same reaction is conducted in THF solution, the alkyl-for-aryl metathesis process appears to occur without the intermediate formation of the ionic gallocenium product.

The gallane 13 crystallizes in the space group $P 2_{1} / n$ and exhibits no unusually short intermolecular contacts. The molecular structure of $\mathbf{1 3}$ is depicted in Fig. 11 and the values of important metrical and crystallographic parameters are listed in Tables 5 and 6. Overall, the arrangement of the substituents in $\mathbf{1 3}$ is obviously related to those of the methylated starting material 11 in the sense that both structures feature one $\eta^{1}-\mathrm{Cp}^{*}$ substituent and one $\eta^{2}-\mathrm{Cp}^{*}$ group (Fig. 11). Similarly, the $\mathrm{C}-\mathrm{C}$ distances in both the $\eta^{1}-\mathrm{Cp}^{*}$ group and the $\eta^{2}-\mathrm{Cp} \mathrm{p}^{*}$ substituent again suggest considerably more delocalized $\pi$-systems than those observed for the $\sigma$-bonded rings in compounds such as $\mathbf{9}$ and $\mathbf{1 0 .}$

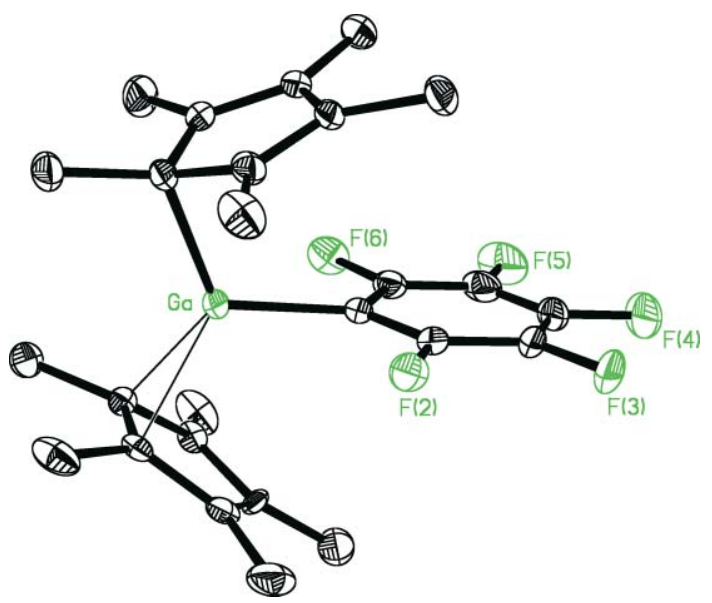

Fig. 11 Thermal ellipsoid plot (30\% probability surface) for 13; only the highest occupancy component of a two-site disorder of the $\eta^{2}-\mathrm{Cp}^{*}$ ring is shown.

Given that $\mathrm{B}\left(\mathrm{C}_{6} \mathrm{~F}_{5}\right)_{3}$ and other perfluoroaryl boranes are known to serve as chloride ion abstractors from certain chlorinated organic molecules ${ }^{33,34}$ and transition metal complexes, ${ }^{35,36}$ we attempted to use $\mathrm{B}\left(\mathrm{C}_{6} \mathrm{~F}_{5}\right)_{3}$ for the generation of salts of the type $3\left[\mathbf{C l B}\left(\mathbf{C}_{6} \mathbf{F}_{5}\right)_{3}\right]$. However, when $\mathrm{CH}_{2} \mathrm{Cl}_{2}$ solutions of 9 were treated 
Table 5 Crystallographic data for compounds 13, 14 and 16

\begin{tabular}{|c|c|c|c|}
\hline Compound & $\mathrm{Cp}_{2}{ }_{2} \mathrm{Ga}\left(\mathrm{C}_{6} \mathrm{~F}_{5}\right)$ & $\mathrm{Cp} * \mathrm{GaCl}\left(\mathrm{C}_{6} \mathrm{~F}_{5}\right)$ & $\mathrm{Cp}^{*}{ }_{2} \mathrm{GaCl}_{2} \mathrm{GaCp}^{*}\left(\mathrm{C}_{6} \mathrm{~F}_{5}\right)$ \\
\hline Compound number & 13 & 14 & 16 \\
\hline Empirical formula & $\mathrm{C}_{26} \mathrm{H}_{30} \mathrm{~F}_{5} \mathrm{Ga}$ & $\mathrm{C}_{16} \mathrm{H}_{15} \mathrm{ClF}_{5} \mathrm{Ga}$ & $\mathrm{C}_{36} \mathrm{H}_{45} \mathrm{Cl}_{2} \mathrm{~F}_{5} \mathrm{Ga}_{2}$ \\
\hline Formula weight & 507.22 & 407.45 & 783.06 \\
\hline Temperature/K & $133(2)$ & $153(2)$ & $153(2)$ \\
\hline Wavelength/Å & 0.71073 & 0.71073 & 0.71073 \\
\hline Crystal system & Monoclinic & Triclinic & Monoclinic \\
\hline Space group & $P 2_{1} / n$ & $P-1$ & $P 2_{1} / n$ \\
\hline \multicolumn{4}{|l|}{ Unit cell dimensions } \\
\hline$a / \AA$ & $9.7661(2)$ & $10.8805(7)$ & $16.844(3)$ \\
\hline$b / \AA$ & $16.3514(4)$ & $11.0468(8)$ & $13.772(3)$ \\
\hline$c / \AA$ & $15.2095(4)$ & $14.4924(13)$ & $17.627(4)$ \\
\hline$a /{ }^{\circ}$ & 90 & $81.353(6)$ & 90 \\
\hline$\beta /{ }^{\circ}$ & $95.3840(10)$ & $82.605(6)$ & $118.04(3)$ \\
\hline$\gamma /{ }^{\circ}$ & 90 & $77.414(5)$ & 90 \\
\hline Volume $/ \AA^{3}$ & $2418.08(10)$ & $1672.4(2)$ & $3609.1(13)$ \\
\hline$Z$ & 4 & 4 & 4 \\
\hline Calculated density $/ \mathrm{g} \mathrm{cm}^{-3}$ & 1.393 & 1.618 & 1.441 \\
\hline Absorption coefficient $/ \mathrm{mm}^{-1}$ & 1.187 & 1.849 & 1.691 \\
\hline$F(000)$ & 1048 & 816 & 1608 \\
\hline Crystal size/mm & $0.20 \times 0.20 \times 0.10$ & $0.4 \times 0.4 \times 0.4$ & $0.4 \times 0.4 \times 0.4$ \\
\hline Theta range for data collection $/^{\circ}$ & 2.96 to 27.48 & 1.43 to 27.50 & 2.96 to 27.53 \\
\hline \multirow{3}{*}{ Limiting indices } & $-11<h<12$ & $-1 \leq h \leq 14$ & $-21<h<17$ \\
\hline & $-19 \leq k \leq 21$ & $-14<k<14$ & $-15<k<17$ \\
\hline & $-19 \leq l \leq 19$ & $-18 \leq l \leq 18$ & $-19 \leq l \leq 22$ \\
\hline Reflections collected/unique & $3306 \overline{4} / 5 \overline{518}$ & $7954 / 7112$ & $18562 / 8235$ \\
\hline$R_{\text {int }}$ & 0.0479 & 0.0354 & 0.1238 \\
\hline Data/restraints/parameters & $5518 / 0 / 330$ & $7112 / 0 / 425$ & $8235 / 0 / 421$ \\
\hline Goodness-of-fit on $F^{2}$ & 1.033 & 0.959 & 1.002 \\
\hline Final $R$ indices $[I>2 \sigma(I)]$ & $R_{1}=0.0403, w R_{2}=0.0744$ & $R_{1}=0.0756, w R_{2}=0.1854$ & $R_{1}=0.0539, w R_{2}=0.0960$ \\
\hline$R$ indices (all data) & $R_{1}=0.0634, w R_{2}=0.0858$ & $R_{1}=0.1146, w R_{2}=0.2072$ & $R_{1}=0.1134, w R_{2}=0.1165$ \\
\hline Largest diff. peak and hole/e $\AA^{-3}$ & 0.441 and -0.524 & 1.458 and -2.687 & 0.589 and -0.627 \\
\hline
\end{tabular}

Table 6 Bond distances $(\AA)$ and angles $\left(^{\circ}\right)$ for compounds 13,14 and 16

\begin{tabular}{|c|c|c|c|c|c|c|}
\hline Compound & $\mathrm{Cp}_{2}{ }_{2} \mathrm{Ga}\left(\mathrm{C}_{6} \mathrm{~F}_{5}\right)$ & Compound & $\mathrm{Cp} * \mathrm{GaCl}\left(\mathrm{C}_{6} \mathrm{~F}_{5}\right)$ & & $\mathrm{Cp}_{2}{ }_{2} \mathrm{GaCl}_{2} \mathrm{GaCp}^{*}\left(\mathrm{C}_{6} \mathrm{~F}_{5}\right)$ & \\
\hline $\mathrm{Ga}-\mathrm{Ar}$ & $1.985(2)$ & $\mathrm{Ga}-\mathrm{Ar}$ & $\begin{array}{l}\text { Mol. } 1 \\
1.970(6)\end{array}$ & $\begin{array}{l}\text { Mol. 2 } \\
1.973(7)\end{array}$ & $\mathrm{Cp}_{2}{ }_{2} \mathrm{Ga}$ & $\begin{array}{l}\mathrm{GaCp}^{*}\left(\mathrm{C}_{6} \mathrm{~F}_{5}\right) \\
1.974(4)\end{array}$ \\
\hline $\mathrm{C}_{i p s o}-\mathrm{Ga}-\mathrm{C}_{2(12)}$ & $123.63(7)$ & $\begin{array}{l}\mathrm{Ga}-\mathrm{Cl}_{\text {bridging }} \\
\mathrm{Ga}-\mathrm{Cl}_{\text {bridging }}\end{array}$ & $\begin{array}{l}2.3765(19) \\
2.3605(17)\end{array}$ & $\begin{array}{l}2.3680(19) \\
2.3614(17)\end{array}$ & $\begin{array}{l}2.5071(11) \\
2.4632(11)\end{array}$ & $\begin{array}{l}2.3345(10) \\
2.3399(11)\end{array}$ \\
\hline $\mathrm{C}_{i p s o}-\mathrm{C}_{\alpha}$ & $1.470(3)$ & $\mathrm{C}_{i p s o}-\mathrm{C}_{\alpha}$ & $1.481(9)$ & $1.461(9)$ & $1.473(6)$ & $1.483(6)$ \\
\hline $\mathrm{C}_{i p s o}-\mathrm{C}_{a}$ & $1.472(3)$ & $\mathrm{C}_{i p s o}-\mathrm{C}_{\alpha}$ & $1.438(10)$ & $1.457(10)$ & $1.480(6)$ & $1.487(6)$ \\
\hline $\mathrm{C}_{\alpha}-\mathrm{C}_{\beta}$ & $1.371(3)$ & $\mathrm{C}_{\alpha}-\mathrm{C}_{\beta}$ & $1.366(10)$ & $1.366(10)$ & $1.357(6)$ & $1.359(6)$ \\
\hline $\mathrm{C}_{\alpha}-\mathrm{C}_{\beta}$ & $1.374(3)$ & $\mathrm{C}_{\alpha}-\mathrm{C}_{\beta}$ & $1.381(9)$ & $1.400(10)$ & $1.359(6)$ & $1.362(7)$ \\
\hline $\mathrm{C}_{\beta}-\mathrm{C}_{\beta}$ & $1.432(4)$ & $\mathrm{C}_{\beta}-\mathrm{C}_{\beta}$ & $1.451(10)$ & $1.420(10)$ & $1.451(7)$ & $1.443(7)$ \\
\hline $\begin{array}{l}\mathrm{C}_{\mathrm{Me}}-\mathrm{C}_{i p s o}-\mathrm{Ga}-\mathrm{C}_{2(12)} \\
\text { Ring } 2\end{array}$ & $1.3(3)$ & $\begin{array}{l}\mathrm{C}_{\mathrm{Me}}-\mathrm{C}_{i p s o}-\mathrm{Ga}-\mathrm{C}_{i p s o} \\
\text { Ring } 2\end{array}$ & $178.2(5)$ & $-179.7(5)$ & $-172.3(3)$ & $178.9(3)$ \\
\hline $\mathrm{C}_{\alpha}-\mathrm{C}_{\beta}$ & $1.466(13)$ & $\mathrm{C}_{\beta}-\mathrm{C}_{\beta}$ & & & $1.469(6)$ & \\
\hline $\mathrm{C}_{\alpha}-\mathrm{C}_{\beta}^{\prime}$ & $1.457(12)$ & $\mathrm{C}_{\mathrm{Me}}^{-}-\mathrm{C}_{i p s o}-\mathrm{Ga}-\mathrm{C}_{i p s o}$ & & & $-170.5(3)$ & \\
\hline
\end{tabular}


with equimolar quantities of $\mathrm{B}\left(\mathrm{C}_{6} \mathrm{~F}_{5}\right)_{3}$ in the same solvent, the only isolable products were those that resulted from the transfer of $\mathrm{C}_{6} \mathrm{~F}_{5}$ groups to the gallium centers. However, in contrast to the situation outlined for 13, it appears that the ligand exchange reactions often involve the cleavage of the $\mathrm{Ga}-\mathrm{Cp}^{*}$ bonds instead of the $\mathrm{Ga}-\mathrm{Cl}$ bonds. For example, crystals of the arylchlorogallane $\mathrm{Cp} * \mathrm{GaCl}\left(\mathrm{C}_{6} \mathrm{~F}_{5}\right) \mathbf{1 4}$ were obtained upon workup of one such reaction mixture. The molecular structure of $\mathbf{1 4}$ is illustrated in Fig. 12 and the values of important metrical parameters are listed in Table 6. Several noteworthy features are apparent for the molecular structure of 14. There are two crystallographically-independent molecules in the asymmetric unit and each $\mathrm{Cp} * \mathrm{GaCl}\left(\mathrm{C}_{6} \mathrm{~F}_{5}\right)$ fragment represents part of a centrosymmetric chlorine-bridged dimer. While the $\mathrm{Ga}-\mathrm{Cl}$ distances are comparable, the $\mathrm{C}-\mathrm{C}$ distances in the $\mathrm{Cp}^{*}$ groups of $\mathbf{1 4}$ indicate that the rings possess $\pi$-systems that are considerably more delocalized than those of the chloride-bridged dimeric gallane 9 and are probably best described as being attached to the Ga centers in an $\eta^{3}$ bonding mode. It is worth noting that $\mathrm{Cp} * \mathrm{AlCl}\left(\mathrm{C}_{6} \mathrm{~F}_{5}\right)(\mathbf{1 5})$, the aluminum analogue of $\mathbf{1 4}$, is obtained in a similar fashion when 7 is treated with $\mathrm{B}\left(\mathrm{C}_{6} \mathrm{~F}_{5}\right)_{3}$ (see the ESI for structural details). $\dagger$
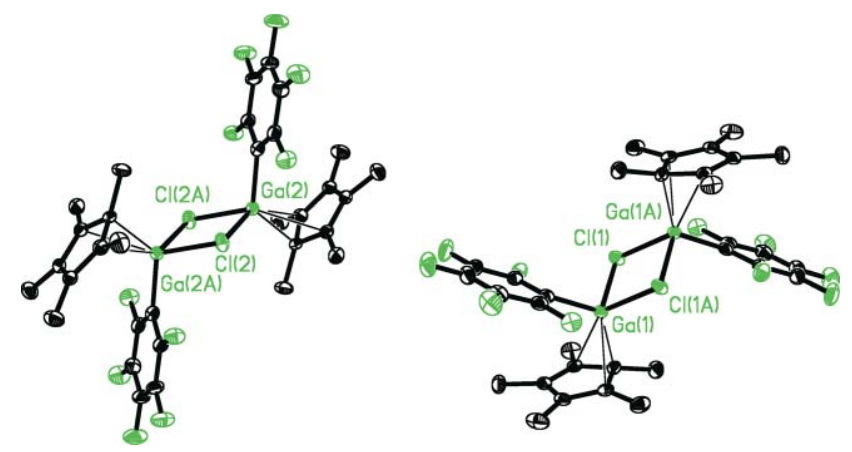

Fig. 12 Thermal ellipsoid plots (30\% probability surface) for $\mathbf{1 4}$

A related, but much more interesting and informative product was also isolated from one such preparation. The dinuclear compound $\mathrm{Cp}^{*}{ }_{2} \mathrm{Ga}(\mu-\mathrm{Cl})_{2} \mathrm{GaCp} *\left(\mathrm{C}_{6} \mathrm{~F}_{5}\right)(\mathbf{1 6})$ may be considered to be an analogue of the dimer $[\mathbf{1 4}]_{2}$ in which only one of the $\mathrm{Cp}^{*}$ groups has been replaced by a pentafluorophenyl substituent. A depiction of the molecular structure of $\mathbf{1 6}$, which crystallizes in the space group $P 2_{1} / \mathrm{n}$, is presented in Fig. 13 and the values of important metrical parameters are listed in Table 6 . The structure

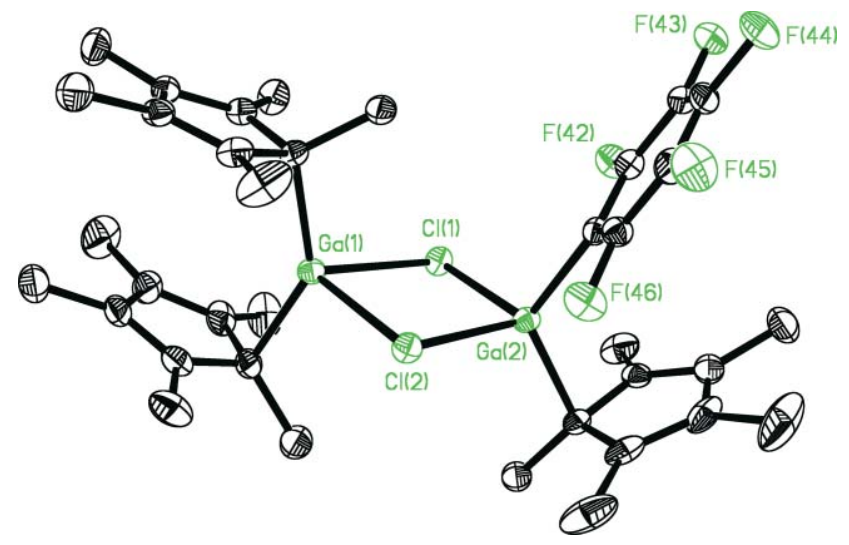

Fig. 13 Thermal ellipsoid plot (30\% probability surface) for $\mathbf{1 6}$. contains a $\mathrm{Cp}_{2}{ }_{2} \mathrm{Ga}$ moiety linked by two bridging $\mathrm{Cl}$ atoms to a $\mathrm{GaCp} *\left(\mathrm{C}_{6} \mathrm{~F}_{5}\right)$ fragment. Both $\mathrm{Cp}^{*}$ rings in the $\mathrm{Cp}^{*}{ }_{2} \mathrm{Ga}$ moiety are best described as being linked to the $\mathrm{Ga}$ atom in an $\eta^{1}(\sigma)$ manner. Overall, the geometry of this fragment bears a close resemblance to those of the $\mathrm{Cp}^{*} \mathrm{Ga}$ fragments in 9. Likewise, the $\mathrm{GaCp} *\left(\mathrm{C}_{6} \mathrm{~F}_{5}\right)$ unit in $\mathbf{1 4}$ is very similar to the corresponding fragments in $\mathbf{1 4}$ with the exception that the $\mathrm{Cp}^{*}$ group is "slipped" and is probably most aptly described as being $\eta^{1}(\sigma)$-bonded to the Ga center. The most unusual feature of the structure of $\mathbf{1 6}$ is the non-equality in the distances between the different gallium atoms and the bridging chlorine atom: the $\mathrm{Cl}-\mathrm{Ga}(1)$ distances (in the $\mathrm{Cp}_{2}^{*} \mathrm{Ga}$ fragment) of 2.4632(11) and 2.5071(11) $\AA$ are both considerably longer than either of the $\mathrm{Cl}-\mathrm{Ga}$ (2) (in the GaCp* $\left(\mathrm{C}_{6} \mathrm{~F}_{5}\right)$ fragment) distances of 2.3345(10) and 2.3399(11) $\AA$. However, the most important insight provided by the molecular structure $\mathbf{1 6}$ is the contrast that it provides with the related aluminum species of overall composition $\mathrm{Cp}_{3}{ }_{3} \mathrm{Al}_{2} \mathrm{Cl}_{3}$. The latter exists as an ion-separated salt of the form $2\left[\mathbf{A l C l}_{3} \mathbf{C} \mathbf{p}^{*}\right]$ and features an undistorted decamethylaluminocenium cation. ${ }^{7}$ Conversely, the metrical parameters for $\mathbf{1 6}$ suggest that the molecule can be considered either as a polarized covalently-bonded neutral "dimeric" gallium species or, somewhat less convincingly, as an exceptionally strongly-associated contact ion pair of $3\left[\mathbf{G a C l}_{2}\left(\mathbf{C}_{6} \mathbf{F}_{5}\right) \mathbf{C p}^{*}\right]$. In either case, it is clear that gallocenium salts (and compounds containing putative gallocenium cations) behave in a significantly different fashion than those of either of the lighter congeners.

Following the initial computational studies on aluminnocenium cations $^{37}$ and the calculations that were included in our initial reports of the crystal structures of $\mathbf{1}\left[\mathbf{A l C l}_{4}\right]^{6}$ and $\mathbf{3}\left[\mathbf{B F} \mathbf{F}_{4}\right],{ }^{14}$ several computational investigations have appeared in which the nature of the bonding and the hapticity preferences ${ }^{24}$ of group 13 metallocenium cations ${ }^{25}$ and analogous species ${ }^{38-40}$ were examined. In the present paper, we focus on the density functional theory (DFT) optimized structures for cations $\mathbf{1}^{+}-\mathbf{3}^{+}$(using the computational models $\mathbf{1}^{\prime+}-\mathbf{3}^{\prime+}$ ) and, more importantly, we have examined the nature of the frontier orbitals (Kohn Sham) in order to rationalize the differing behavior of this isovalent series of cations.

The experimentally observed $\eta^{5}, \sigma$-bonded structure of the decamethylborocenium cation is reproduced quite accurately in $C_{\mathrm{s}}$ symmetry by the DFT method as illustrated in Fig. 14 and demonstrated by the selected metrical parameters that are listed in Table 7. The only obvious discrepancy between the computed and experimental structures is the somewhat more "bent" appearance of the $\eta^{1}(\sigma)$-bonded $C p^{*}$ ring; the $\mathrm{B}-\mathrm{C}_{i p s o}-\mathrm{C}_{5 \operatorname{centroid}(\eta 1)}$ angle observed for the tetrachloroaluminate salt of $\mathbf{1}^{+}$is $114.30(2)^{\circ}\left[111.98(2)^{\circ}\right]$, which is somewhat smaller than the angle of $123.6^{\circ}$ calculated for $\mathbf{1}^{\prime+}$. This minor difference can be attributed to the fact that $\mathbf{1}^{\prime+}$ is a gas-phase model whereas the experimental structure was determined in the solid state and is thus subject to a plethora of packing interactions. In any case, the apparent difference between the two structures is quite minor and the overall agreement attests to the suitability of the DFT method that we have employed.

Geometry optimization of the computational model of the decamethylaluminocenium cation $\left(\mathbf{2}^{+}\right)$in the point group $D_{5 \mathrm{~d}}$ reproduces the experimental $\eta^{5}, \eta^{5}$-bonded structure of $\mathbf{2}^{+}$almost exactly both in terms of the conformation (Fig. 15) and the computed metrical parameters (Table 7). Such excellent agreement is perhaps not unexpected given the observation that the molecular structures of cations of $\mathbf{2}^{+}$appear to be indistinguishable regardless 


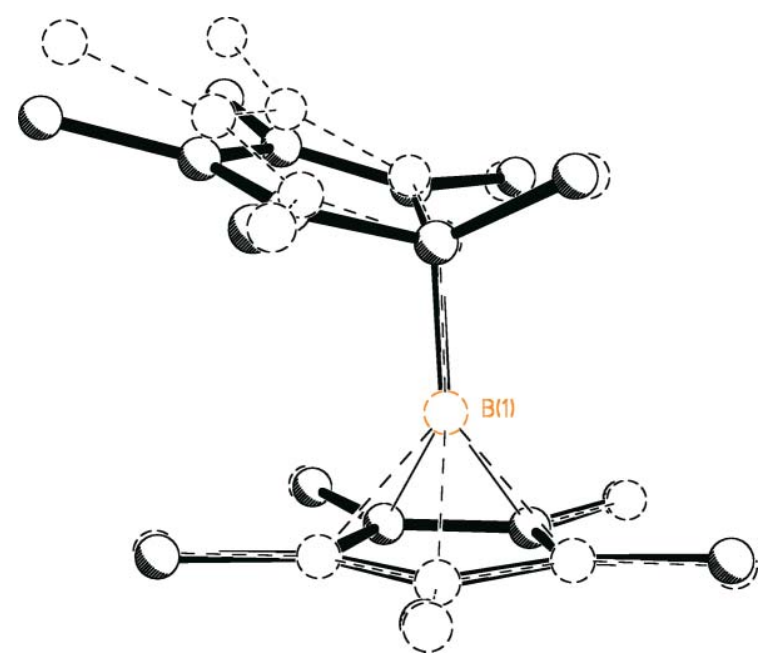

Fig. 14 Overlay of the experimentally determined structure $\mathbf{1}^{+}$(solid lines) and the DFT optimized structure $\mathbf{1}^{\prime+}$ (dashed lines).

of the nature of the counter anions in virtually all of the decamethylaluminocenium salts that have been examined by $\mathrm{X}$ ray crystallography thus far. It is noteworthy that the perfectly staggered structure predicted computationally is preferentially adopted even in the absence of crystallographically-imposed symmetry restraints hence this particular conformation appears to be remarkably robust.

In contrast to the excellent agreement observed for the experimental and theoretical models observed for the lighter congeners, the calculated structure for the decamethylgallocenium cation

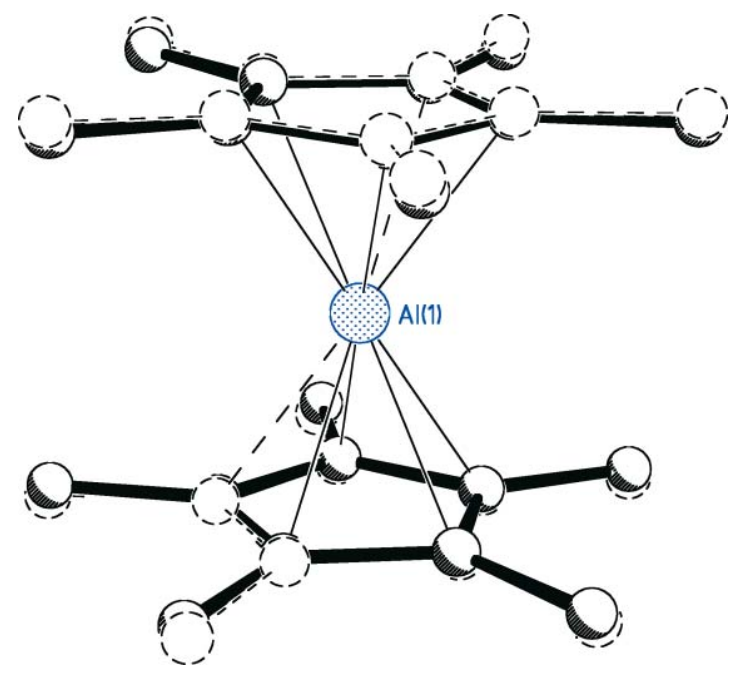

Fig. 15 Overlay of the experimentally determined structure $2^{+}$(solid lines) and the DFT optimized structure $\mathbf{2}^{\prime+}$ (dashed lines).

model $\mathbf{3}^{\prime+}$ is significantly different than either of the experimental structures described above. As illustrated in Fig. 16, the geometryoptimized $C_{\mathrm{s}}$-symmetry model structure $\mathbf{3}^{\prime+}$ predicts a $\eta^{5}, \sigma$-bonded structure that is very similar in appearance to that of the boron analogue and is clearly distinct from that of the most similar of the solid-state structures. Perhaps the most significant difference, given the close agreement between the arrangements of the $\mathrm{Cp}^{*}$ rings in both of the experimental compounds (Fig. 10), is the non-parallel arrangement of $\mathrm{Cp}^{*}$ rings in $\mathbf{3}^{\prime+}$. Despite the obvious distortions, the model compound does accurately predict many

Table 7 Selected calculated orbital energies $(\mathrm{eV})$, bond distances $(\AA)$ and angles $\left({ }^{\circ}\right)$ for geometry optimized model compounds $\mathbf{1}^{\prime+}, \mathbf{2}^{\prime+}$ and $\mathbf{3}^{\prime+}$

\begin{tabular}{|c|c|c|c|c|c|}
\hline$\frac{\text { Model }}{\text { Model number }}$ & $\frac{\mathrm{Cp}^{*}{ }_{2} \mathrm{~B}^{+}}{\mathbf{1}^{\prime+}}$ & & $\frac{\mathrm{Cp}_{2}{ }_{2} \mathrm{Al}^{+}}{2^{\prime+}}$ & & $\frac{\mathrm{Cp}_{2}{ }_{2} \mathrm{Ga}^{+}}{3^{\prime}+}$ \\
\hline Symmetry & $C_{\mathrm{s}}$ & & $D_{5 \mathrm{~d}}$ & & $C_{\mathrm{s}}$ \\
\hline$E_{\text {номо }} / \mathrm{eV}$ & -7.61 & & -8.71 & & -7.95 \\
\hline$E_{\text {LUMO }} / \mathrm{eV}$ & -4.38 & & -4.98 & & -5.80 \\
\hline HOMO-LUMO/eV & 3.23 & & 3.73 & & 2.15 \\
\hline Ring 1 & & Ring 1 & & Ring 1 & \\
\hline $\mathrm{B}-\mathrm{C}_{i p s o}$ & 1.592 & $\mathrm{Al}-\mathrm{Cp}{ }^{*}{ }_{\text {cent }}$ & 1.802 & $\mathrm{Ga}-\mathrm{C}_{i p s o}$ & 2.019 \\
\hline $\mathrm{C}_{i p s o}-\mathrm{C}_{\alpha}$ & 1.538 & $\mathrm{C}-\mathrm{C}$ & 1.452 & $\mathrm{C}_{i p s o}-\mathrm{C}_{\alpha}$ & 1.511 \\
\hline $\mathrm{C}_{i p s o}-\mathrm{C}_{\alpha}$ & 1.538 & $\mathrm{C}-\mathrm{C}$ & 1.452 & $\mathrm{C}_{i p s o}-\mathrm{C}_{\alpha}$ & 1.511 \\
\hline $\mathrm{C}_{\alpha}-\mathrm{C}_{\beta}$ & 1.371 & $\mathrm{C}-\mathrm{C}$ & 1.452 & $\mathrm{C}_{\alpha}-\mathrm{C}_{\beta}$ & 1.380 \\
\hline $\mathrm{C}_{\alpha}-\mathrm{C}_{\beta}$ & 1.371 & $\mathrm{C}-\mathrm{C}$ & 1.452 & $\mathrm{C}_{\alpha}-\mathrm{C}_{\beta}$ & 1.380 \\
\hline $\mathrm{B}-\mathrm{C}_{i p s o}$ & 1.781 & $\mathrm{Al}-\mathrm{C}$ & 2.185 & $\mathrm{Ga}-\mathrm{C}_{i p s o}$ & 2.274 \\
\hline $\mathrm{B}-\mathrm{C}_{\alpha}=0$ & 1.793 & $\mathrm{Al}-\mathrm{C}$ & 2.185 & $\mathrm{Ga}-\mathrm{C}_{\alpha}$ & 2.249 \\
\hline $\mathrm{B}-\mathrm{C}_{\alpha}$ & 1.793 & $\mathrm{Al}-\mathrm{C}$ & 2.185 & $\mathrm{Ga}-\mathrm{C}_{\alpha}$ & 2.249 \\
\hline $\mathrm{B}-\mathrm{C}_{\beta}$ & 1.773 & $\mathrm{Al}-\mathrm{C}$ & 2.185 & $\mathrm{Ga}-\mathrm{C}_{\beta}$ & 2.203 \\
\hline $\mathrm{B}-\mathrm{C}_{\beta}$ & 1.773 & $\mathrm{Al}-\mathrm{C}$ & 2.185 & $\mathrm{Ga}-\mathrm{C}_{\beta}$ & 2.203 \\
\hline $\mathrm{C}_{i p s o}-\mathrm{C}_{\alpha}$ & 1.445 & $\mathrm{C}-\mathrm{C}$ & 1.452 & $\mathrm{C}_{i p s o}-\mathrm{C}_{\alpha}$ & 1.453 \\
\hline $\mathrm{C}_{i p s o}-\mathrm{C}_{\alpha}$ & 1.445 & $\mathrm{C}-\mathrm{C}$ & 1.452 & $\mathrm{C}_{i p s o}-\mathrm{C}_{\alpha}$ & 1.453 \\
\hline $\mathrm{C}_{\alpha}-\mathrm{C}_{\beta}$ & 1.446 & $\mathrm{C}-\mathrm{C}$ & 1.452 & $\mathrm{C}_{\alpha}-\mathrm{C}_{\beta}$ & 1.457 \\
\hline $\mathrm{C}_{\alpha}-\mathrm{C}_{\beta}$ & 1.446 & $\mathrm{C}-\mathrm{C}$ & 1.452 & $\mathrm{C}_{\alpha}-\mathrm{C}_{\beta}$ & 1.457 \\
\hline $\mathrm{C}_{\beta}-\mathrm{C}_{\beta}$ & 1.449 & $\mathrm{C}-\mathrm{C}$ & 1.452 & $\mathrm{C}_{\beta}-\mathrm{C}_{\beta}$ & 1.462 \\
\hline
\end{tabular}




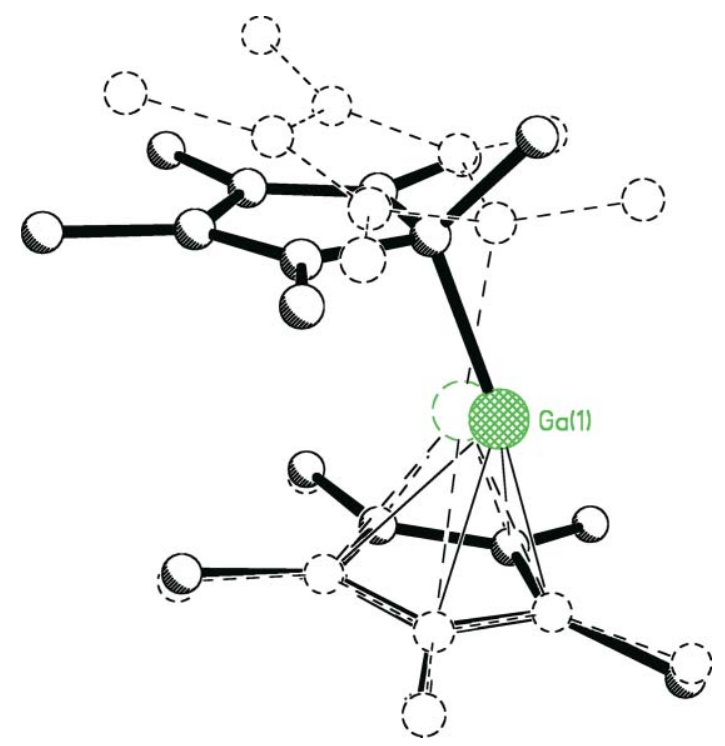

Fig. 16 Overlay of the experimentally determined structure $3^{+}$from $3\left[\mathrm{AlCl}_{4}\right]$ (solid lines) and the DFT optimized structure $3^{\prime+}$ (dashed lines).

of the bond distances. Moreover, the computed structure is likely to be an accurate representation of the gas-phase structure. As indicated above, there are clearly several close interactions between the cations of $\mathbf{3}^{+}$and the anions in both the tetrafluoroborate and tetrachloroaluminate salts. We have previously demonstrated that it requires very little energy to distort the model cation $\mathrm{Cp}_{2} \mathrm{Ga}^{+},{ }^{14}$ thus it is almost certain that the differences between the observed and calculated structures are attributable to interionic interactions and solid-state packing effects. It therefore appears that the isolation of a decamethylgallocenium cation having a structure more similar to that of the calculated model would undoubtedly require the use of an exceedingly stable and essentially non-coordinating counter anion.

While the models $\mathbf{1}^{\prime+}$ and $\mathbf{3}^{++}$appear to be similar in terms of their superficial structural features, in particular the $\eta^{5}, \sigma$-bonded $\mathrm{Cp}^{*}$ rings, the essentially inert nature of the decamethylborocenium cation (and the aluminum analogue) contrasts sharply with the highly-reactive nature of the decamethylgallocenium cation. In an attempt to rationalize these reactivity differences, we have examined the frontier orbitals of the three model cations. As illustrated in Fig. 17, the highest occupied molecular orbital (HOMO) on each of the group 13 metallocenium cations is composed exclusively of combinations of atomic orbitals on the $\mathrm{Cp}^{*}$ ring, as is typical of many other main group metallocenes. While the more symmetric nature of the structure of the $\mathrm{Al}$ cation causes the appearance of the HOMO to be somewhat different than those of the $\mathrm{B}$ and $\mathrm{Ga}$ analogues, the correspondence between the HOMO of the borocenium cation and that of the gallocenium cation is striking.

As pointed out above, the structures and reactivity patterns of cations $\mathbf{1}^{+}, \mathbf{2}^{+}$and $\mathbf{3}^{+}$exhibit considerable diversity. For example, the structures of $\mathbf{1}^{+}$and $\mathbf{2}^{+}$are not deformed as easily as that of $\mathbf{3}^{+}$. Moreover, the salts of $\mathbf{1}^{+}$and $\mathbf{2}^{+}$feature minimal cation-anion interactions while the opposite is true for $\mathbf{3}^{+}$. From the standpoint of reactivity, salts of $\mathbf{1}^{+}$do not initiate the polymerization of ethylene or styrene whereas salts of $\mathbf{2}^{+}$are potent initiators. It was anticipated that the origin of these differences might be in the nature of the lowest unoccupied molecular orbitals (LUMO's) of these group 13 cations. The LUMO's of $\mathbf{1}^{\prime+}, \mathbf{2}^{\prime+}$ and $\mathbf{3}^{\prime+}$ are displayed in Fig. 18.

Whereas the molecular structures and HOMOs of $\mathbf{1}^{\prime+}$ and $\mathbf{3}^{\prime+}$ are quite similar in appearance, their respective LUMOs
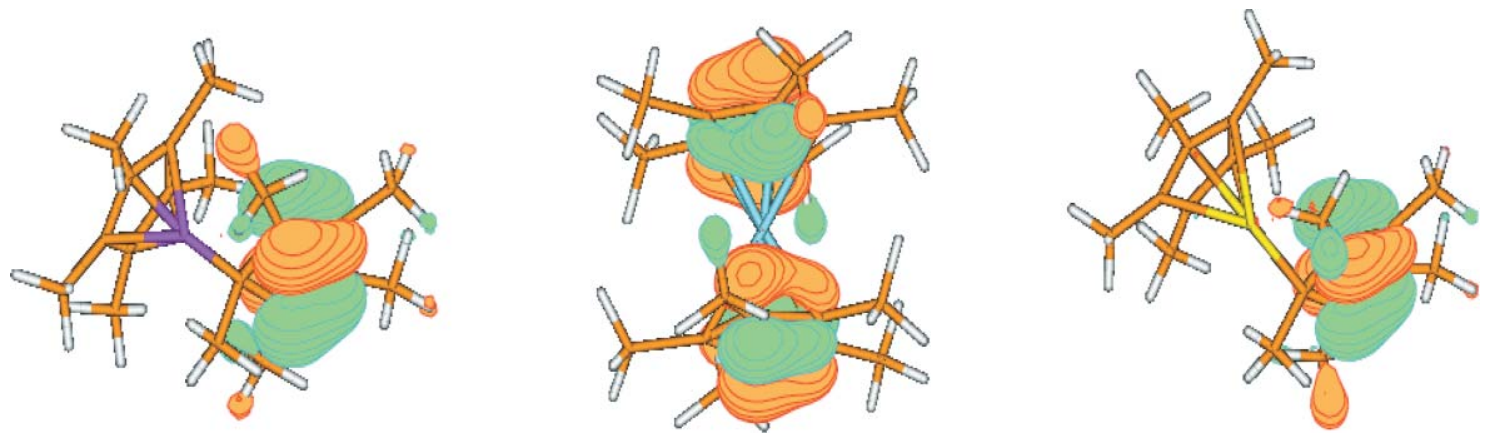

Fig. 17 Molden renderings of the highest occupied molecular orbital (HOMO) of $\mathbf{1}^{\prime+}$ (left), $\mathbf{2}^{\prime+}$ (center) and $\mathbf{3}^{\prime+}$ (right).
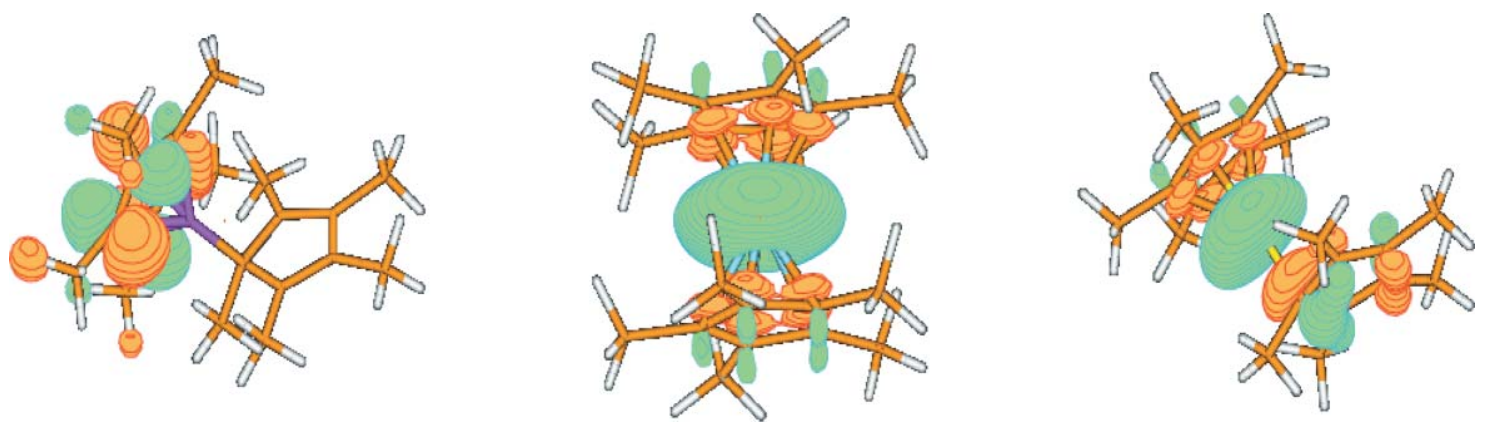

Fig. 18 Molden renderings of the lowest unoccupied molecular orbital (LUMO) in $\mathbf{1}^{\prime+}$ (left), $\mathbf{2}^{\prime+}$ (center) and $\mathbf{3}^{\prime+}$ (right). 
are conspicuously different. The LUMO of $\mathbf{1}^{\prime+}$ is based almost exclusively on the $\mathrm{Cp}^{*}$ ring and appears to have virtually no contribution from atomic orbitals on the boron center. In contrast, the LUMO of $\mathbf{3}^{\prime+}$ is primarily a metal-based orbital, the largest lobe of which comprises a slightly-distorted ellipsoid centered on the gallium atom. In spite of the structural differences, it is clear that the LUMO of $\mathbf{3}^{++}$bears a greater resemblance to that of $\mathbf{2}^{++}$than to that of $\mathbf{1}^{\prime+}$. Furthermore, examination of the calculated LUMO energies of each of the model cations (Table 7), reveals that the LUMO for the gallium cation $\mathbf{3}^{\prime+}$ is considerably lower in energy than those of either of the lighter analogues. As a consequence, the gallocenium cation $\mathbf{3}^{\prime+}$ is anticipated to be a superior acceptor than either the boron or aluminum congeners. Thus, in light of both the composition and the energy of the LUMO in $\mathbf{3}^{+}$, it is not surprising that the gallocenium cation behaves as metal-based acceptor toward the counter anions in the salts described above.

Finally, the energy differences between the HOMO and LUMO of each of the model decamethylmetallocenium cations provides additional insights into their relative stabilities. As shown in Table 7, the HOMO-LUMO gap is the largest for the aluminocenium cation $\mathbf{2}^{\prime+}$ and the borocenium analogue $\mathbf{1}^{\prime+}$ has a slightly smaller energy difference. However, the gallocenium cation $3^{\prime+}$ has a considerably smaller HOMO-LUMO gap than either of the lighter congeners which suggests that it would likely be a significantly less stable compound.

Overall, the DFT calculations help to rationalize why the decamethylgallocenium cation exhibits some properties that appear to be intermediate between those of its two lighter congeners: the gallium cation is predicted to adopt a molecular structure analogous to that of the boron cation and an electronic structure that is more similar to that of the aluminum cation. The higher reactivity of the model decamethylgallocenium cation is attributable to the modest HOMO/LUMO gap.

\section{Experimental}

\section{General procedures}

Pentamethylcyclopentadiene $(\mathrm{Cp} * \mathrm{H})$ was synthesized according to a published procedure. ${ }^{41}$ Tris(pentafluorophenyl)borane, gallium(III) chloride and gallium(III) bromide were purchased from Strem Chemicals and used as received. All other chemicals and reagents were obtained from the Aldrich Chemical Company and were used as received. Diethyl ether, hexanes, pentane, toluene and tetrahydrofuran were dried over sodium with benzophenone ketyl and $\mathrm{CH}_{2} \mathrm{Cl}_{2}$ was dried over $\mathrm{CaH}_{2}$. All solvents were distilled and degassed immediately prior to use. All reagents were handled in argon-filled dryboxes (Vacuum Atmospheres or MBraun) and reactions were performed using standard inert atmosphere techniques. Melting points were recorded on an Electrothermal apparatus and are uncorrected. Elemental analyses were performed by Atlantic Microlabs, Norcross, GA USA. Unless specified otherwise, NMR spectra were recorded at $295 \mathrm{~K}$ on a General Electric QE-300 Fourier transform spectrometer with spectrometer frequencies of $300.19 \mathrm{MHz}$ for ${ }^{1} \mathrm{H}, 75.48 \mathrm{MHz}$ for ${ }^{13} \mathrm{C}, 96.42 \mathrm{MHz}$ for ${ }^{11} \mathrm{~B}, 78.31 \mathrm{MHz}$ for ${ }^{27} \mathrm{Al}$ and $282.72 \mathrm{MHz}$ for ${ }^{19} \mathrm{~F}$. NMR samples were either run immediately following removal from the drybox or in flame-sealed $5 \mathrm{~mm}$ NMR tubes. All chemical shifts are reported in ppm relative to an external standard $\left(\mathrm{SiMe}_{4}\right.$ for ${ }^{1} \mathrm{H}$ and ${ }^{13} \mathrm{C},\left[\mathrm{Al}\left(\mathrm{D}_{2} \mathrm{O}\right)_{6}\right]^{+3}$ for ${ }^{27} \mathrm{Al}, \mathrm{BF}_{3}$. $\mathrm{OEt}_{2}$ for ${ }^{11} \mathrm{~B}$, and $\mathrm{CFCl}_{3}$ for ${ }^{19} \mathrm{~F}$ ). Low-resolution mass spectra (CI, $\mathrm{CH}_{4}$ ) were obtained on a Finnigan MAT TSQ 700 instrument. High-resolution mass spectra $\left(\mathrm{CI}, \mathrm{CH}_{4}\right)$ were obtained on a VG ZAB-VE sector instrument.

The starting materials $\mathrm{MeGaCl}_{2}{ }^{42} \mathrm{Cp}^{*} \mathrm{M} \quad(\mathrm{M}=\mathrm{Li}$, $\mathrm{Na}, \quad \mathrm{K}),{ }^{1} \mathrm{Cp}^{*}{ }_{2} \mathrm{BCl},{ }^{5} \mathrm{Cp}^{*}{ }_{2} \mathrm{BMe},{ }^{15} \mathrm{Cp}^{*}{ }_{2} \mathrm{AlMe},{ }^{10} \quad$ “Cp ${ }_{2} \mathrm{AlCl}$ ", ${ }_{11}$ $\mathrm{Cp}^{*}{ }_{2} \mathrm{GaCl}^{22} \quad \mathrm{Cp}_{3}{ }_{3} \mathrm{Ga},{ }^{29} \quad[\mathrm{Li}]\left[\mathrm{B}\left(\mathrm{C}_{6} \mathrm{~F}_{5}\right)_{4}\right],{ }^{43} \quad\left[\mathrm{Ph}_{3} \mathrm{C}\right]\left[\mathrm{B}\left(\mathrm{C}_{6} \mathrm{~F}_{5}\right)_{4}\right],{ }^{44}$ $\mathrm{Al}\left(\mathrm{C}_{6} \mathrm{~F}_{5}\right)_{3}{ }^{45}$ and $\mathrm{Ga}\left(\mathrm{C}_{6} \mathrm{~F}_{5}\right)_{3}{ }^{45}$ were prepared according to published procedures. The preparations of the salts $\left[\mathrm{Cp}^{*}{ }_{2} \mathrm{~B}\right]\left[\mathrm{AlCl}_{4}\right]^{6}{ }^{6}$ $\left[\mathrm{Cp}_{2}{ }_{2} \mathrm{Al}\right]\left[\mathrm{AlCl}_{4}\right],{ }^{12}$ and $\left[\mathrm{Cp}^{*}{ }_{2} \mathrm{Ga}\right]\left[\mathrm{BF}_{4}\right]^{14}$ have been reported previously.

In most cases, the decomposition products described in the text were characterized solely on the basis of X-ray crystallographic experiments.

\section{Synthesis}

Cp ${ }_{2} \mathbf{B B r}$ (5). Neat $\mathrm{BBr}_{3}(3.76 \mathrm{~g}, 15 \mathrm{mmol})$ was added to a suspension of $\mathrm{C}_{5} \mathrm{Me}_{5} \mathrm{Li}(4.26 \mathrm{~g}, 30.0 \mathrm{mmol})$ in hexane at $-50{ }^{\circ} \mathrm{C}$. The resulting mixture was allowed to warm slowly to room temperature over a period of several hours then refluxed overnight. The reaction mixture was filtered at room temperature and the filtrate was concentrated and cooled to $-20{ }^{\circ} \mathrm{C}$ resulting in a crop of yellow crystals of the desired product. Yield: $35 \%$; mp, decomposes. CI HRMS: calcd for $\mathrm{C}_{20} \mathrm{H}_{30} \mathrm{~B}, 281.2441$; found, 281.2453. NMR $\left(\mathrm{C}_{6} \mathrm{D}_{6}\right):{ }^{1} \mathrm{H}: \delta 1.60\left(\mathrm{~s}, \mathrm{C}_{5} M e_{5}\right) .{ }^{13} \mathrm{C}\left\{{ }^{1} \mathrm{H}\right\}: \delta 13.74$ (s, $\left.\mathrm{C}_{5} M e_{5}\right), 123.83\left(\mathrm{~s}, C_{5} \mathrm{Me}_{5}\right){ }^{11} \mathrm{~B}: \delta 77.8\left(\mathrm{br}, \mathrm{w}^{1 / 2}=370 \mathrm{~Hz}\right)$.

$\mathrm{Cp}^{*}{ }_{2} \mathrm{GaBr}$ (10). In a typical reaction, a solution of $\mathrm{GaBr}_{3}$ $(1.65 \mathrm{~g}, 5.3 \mathrm{mmol})$ in diethyl ether $(100 \mathrm{~mL})$ was added to a slurry of $\mathrm{Cp}^{*} \mathrm{Li}(1.51 \mathrm{~g}, 10.6 \mathrm{mmol})$ in diethyl ether $(100 \mathrm{~mL})$ at room temperature. The reaction mixture was allowed to stir for $48 \mathrm{~h}$, following which the volatiles were removed under reduced pressure. Hexanes were added to the remaining pale yellow solid mixture and the resultant slurry was filtered through Celite ${ }^{\circledR}$ to give a pale yellow filtrate. The latter solution was concentrated to incipient crystallization then placed in a freezer $\left(-20{ }^{\circ} \mathrm{C}\right)$ overnight, which resulted in the formation of a crop of colorless needle-shaped crystals. A typical yield of the first crop of crystals was $0.50 \mathrm{~g},(1.1 \mathrm{mmol}), 22 \%$ yield. The overall yield can be increased by subsequent cycles of concentration and recrystallization. $\mathrm{Mp} 129-130{ }^{\circ} \mathrm{C}$; $\mathrm{MS}\left(\mathrm{CI}, \mathrm{CH}_{4}\right): 418$ to $422(\mathrm{M})^{+}$ $30 \%, 339$ and $341(\mathrm{M}-\mathrm{Br})^{+} 100 \%$, 283 to $287\left(\mathrm{M}-\mathrm{Cp}^{*}\right)^{+} 30 \%$; HRMS (CI, $\mathrm{CH}_{4}$ ): Calcd. for $\mathrm{C}_{20} \mathrm{H}_{30} \mathrm{GaBr}$ 418.078668; Found 418.078178; NMR $\left(\mathrm{C}_{6} \mathrm{D}_{6}\right):{ }^{1} \mathrm{H}, \delta 1.75\left(\mathrm{~s}, \mathrm{C}_{5} M e_{5}\right) ;{ }^{13} \mathrm{C}\left\{{ }^{1} \mathrm{H}\right\}, \delta 12.28$ $\left(\mathrm{s}, \mathrm{C}_{5} M e_{5}\right), \delta 121.53\left(\mathrm{~s}, C_{5} \mathrm{Me}_{5}\right)$.

$\mathbf{C} \mathbf{p}^{*}{ }_{2}$ GaMe (11). In a typical reaction, a solution of $\mathrm{MeGaCl}_{2}$ $(1.49 \mathrm{~g}, 9.6 \mathrm{mmol})$ in diethyl ether solution $(100 \mathrm{~mL})$ was added to a slurry of $\mathrm{Cp} * \operatorname{Li}(2.74 \mathrm{~g}, 19.3 \mathrm{mmol})$ in diethyl ether $(100 \mathrm{~mL})$ at room temperature. The reaction mixture was allowed to stir for $48 \mathrm{~h}$, following which the volatiles were removed under reduced pressure. Hexanes were added to the pale yellow solid residue and the resultant slurry was filtered through Celite ${ }^{\circledR}$ to afford a pale yellow filtrate. The latter solution was concentrated to incipient crystallization, then placed in a freezer $\left(-20^{\circ} \mathrm{C}\right)$ overnight which resulted in the formation of a crop of colorless, block-shaped crystals. The typical yield was $2.15 \mathrm{~g}(6.0 \mathrm{mmol}), 64 \%$; MS (CI, $\left.\mathrm{CH}_{4}\right): 353$ and $355(\mathrm{M}-\mathrm{H})^{+}<1 \%, 339$ and $341(\mathrm{M}-\mathrm{Me})^{+} 100 \%, 219$ 
and $221\left(\mathrm{M}-\mathrm{Cp}^{*}\right)^{+}, 45 \%$; HRMS (CI, $\left.\mathrm{CH}_{4}\right)$ : Calcd. for $\mathrm{C}_{21} \mathrm{H}_{32} \mathrm{Ga}$ $(\mathrm{M}-\mathrm{H})^{+}$, 353.175982, Found, 353.177003; Calcd. for $\mathrm{C}_{20} \mathrm{H}_{30} \mathrm{Ga}$ $(\mathrm{M}-\mathrm{Me})^{+}, 339.160332$, Found, 339.159934; NMR $\left(\mathrm{C}_{6} \mathrm{D}_{6}\right):{ }^{1} \mathrm{H}, \delta$ -1.29 (s, GaMe), $\delta 1.89\left(\mathrm{~s}, \mathrm{C}_{5} M e_{5}\right) ;{ }^{13} \mathrm{C}\left\{{ }^{1} \mathrm{H}\right\}, \delta 1.27$ (s, GaMe), $\delta$ $11.81\left(\mathrm{~s}, \mathrm{C}_{5} M e_{5}\right), \delta 119.90\left(\mathrm{~s}, C_{5} \mathrm{Me}_{5}\right)$.

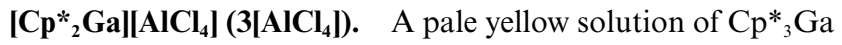
(0.399 $\mathrm{g}, 0.84 \mathrm{mmol})$ in $\mathrm{CH}_{2} \mathrm{Cl}_{2}(80 \mathrm{~mL})$ was added to a stirred slurry of $\mathrm{AlCl}_{3}(0.116 \mathrm{~g}, 0.87 \mathrm{mmol})$ in $\mathrm{CH}_{2} \mathrm{Cl}_{2}$ solution $(20 \mathrm{~mL})$ at room temperature. The bright yellow reaction mixture was stirred until the $\mathrm{AlCl}_{3}$ was completely dissolved/reacted (4 d), following which the solution was concentrated to a volume of ca. $5 \mathrm{~mL}$ by removal of the solvent and volatiles under reduced pressure. The residual liquid was placed in a freezer $\left(-20{ }^{\circ} \mathrm{C}\right)$ which resulted in the formation of a crop of colorless needleshaped crystals of $\mathrm{Cp}^{*}{ }_{2} \mathrm{GaCl}$ (yield $c a$. 85\%; identified by $\mathrm{X}$ ray crystallography). After a further $24 \mathrm{~h}$ of storage, a crop of bright yellow blocks of $\left[\mathrm{Cp}_{2}{ }_{2} \mathrm{Ga}\right]\left[\mathrm{AlCl}_{4}\right]$ was formed (yield ca. $15 \%$; identified by X-ray crystallography). The total yield of product following one week of storage at $-20{ }^{\circ} \mathrm{C}$ was $0.23 \mathrm{~g}$. For $\left[\mathrm{Cp}_{2}{ }_{2} \mathrm{Ga}\right]\left[\mathrm{AlCl}_{4}\right]$ : mp, decomposes at $115-117{ }^{\circ} \mathrm{C}$. HRMS (CI, $\mathrm{CH}_{4}$ ): calcd for $\mathrm{C}_{20} \mathrm{H}_{30} \mathrm{Ga}$, 339.160332; found, 339.159209; calcd for $\mathrm{AlCl}_{4}, 166.856952$; found 166.857138. NMR $\left(\mathrm{CD}_{2} \mathrm{Cl}_{2}\right):{ }^{1} \mathrm{H}$ : $\delta 1.80\left(\mathrm{~s}, \mathrm{C}_{5} \mathrm{Me}_{5}\right) \cdot{ }^{13} \mathrm{C} \mathrm{NMR}\left(75.48 \mathrm{MHz}, \mathrm{CD}_{2} \mathrm{Cl}_{2}\right): \delta 11.9(\mathrm{~s}$, $\left.\mathrm{C}_{5}\left(\mathrm{CH}_{3}\right)_{5}\right), \delta 120.4\left(\mathrm{~s}, \eta^{5}-\mathrm{C}_{5}\left(\mathrm{CH}_{3}\right)_{5}\right)$.

\section{X-Ray crystallography}

Suitable single crystals of each compound were covered with a perfluorinated polyether oil and the X-ray data were collected on either a Nonius Kappa CCD diffractometer or a Siemens P4 diffractometer. The data from the Siemens P4 diffractometer were collected at $213 \mathrm{~K}$ using graphite-monochromated Mo $\mathrm{K} \alpha$ radiation $(\lambda=0.71073 \AA)$. Accurate unit cell parameters were determined by re-centering 25 optimal high angle reflections. Corrections were applied for Lorentz and polarization effects. Three standard reflections were measured every $1800 \mathrm{~s}$ during each data collection, and no decreases in intensities were observed. The data from the Nonius-Kappa CCD diffractometer were collected at $153 \mathrm{~K}$ using an Oxford Cryostream low-temperature device and graphite-monochromated Mo $\mathrm{K} \alpha$ radiation $(\lambda=$ $0.71073 \AA$ A). In each case, corrections were applied for Lorentz and polarization effects. All structures were solved by direct methods using either SIR $97^{46}$ or SHELXS ${ }^{47}$ programs and refined by full-matrix least squares on $F^{2}$ using either the SHELXL ${ }^{47}$ or the WinGX $\mathrm{X}^{48}$ software package. All non-hydrogen atoms were allowed anisotropic thermal motion and hydrogen atoms, which were included at calculated positions, were refined using a riding model and a general isotropic thermal parameter. It should be noted that for the structure of $\mathbf{1 5}$, the $\eta^{2}$-bonded ring was modeled using a 2-site disorder model with occupancies of 68 and $32 \%$ only the site with the highest occupancy is depicted. Renderings of the molecular structures were generated using the SHELXTL ${ }^{49}$ software package and analyses of the data were undertaken with the program PLATON. ${ }^{50}$

\section{Computational methods}

All calculations were performed using the Gaussian98 suite of programs. ${ }^{51}$ Geometry optimizations were completed using the
BP86 $6^{52,53}$ density functional theory (DFT) approach with $6-31 \mathrm{G}^{*}$ basis sets on all $\mathrm{C}$ and $\mathrm{H}$ atoms and $6-31+\mathrm{G}^{*}$ basis sets on $\mathrm{B}, \mathrm{Al}$ and $\mathrm{Ga}$. Drawings of the optimized structures were produced using the SHELXTL software package and depictions of the molecular orbitals were generated using the MOLDEN program. ${ }^{54}$

\section{Conclusions}

Salts containing the decamethylmetallocenium cations for $\mathrm{Cp}^{*}{ }_{2} \mathrm{~B}^{+}, \mathrm{Cp}^{*}{ }_{2} \mathrm{Al}^{+}$and $\mathrm{Cp}_{2}{ }_{2} \mathrm{Ga}^{+}$have been prepared using a variety of precursors and synthetic routes. Crystallographic investigations of the precursor molecules reveal that the structural features of these boron, aluminum and gallium derivatives vary significantly and depend on the size and electronegativity of the group 13 atom. Whereas salt metathesis, halide abstraction and methanide abstraction represent viable routes for the preparation of decamethylborocenium and decamethylaluminocenium salts, acidolysis of a $\mathrm{Cp}^{*}$ group from $\mathrm{Cp}_{3}{ }_{3} \mathrm{Ga}$ proved to be the most reliable synthetic method for decamethylgallocenium salts. While X-ray crystallographic studies reveal that the decamethylborocenium and decamethylaluminocenium salts do not feature unusually short anion-cation interactions, such interactions appear to play a more dominant role in the structures of the corresponding gallium salts. The decamethylgallocenium cations are significantly less stable than either of the lighter congeneric cations, being particularly susceptible to decomposition reactions involving the "backtransfer" of ligands from the counter anions. The observations made on the series of isovalent salts of the type $\left[\mathrm{Cp}^{*}{ }_{2} \mathrm{M}\right]\left[\mathrm{AlCl}_{4}\right]$ $(\mathrm{M}=\mathrm{B}, \mathrm{Al}, \mathrm{Ga})$ highlight the metal-dependent nature of the structural trends of these cations. DFT calculations reveal that, whereas the decamethylgallocenium cation is predicted to adopt a molecular structure similar to that of the decamethylborocenium cation, the electronic structure of the decamethylgallocenium cation is more similar to that of the aluminum analogue. Overall, the decamethylgallocenium cation appears to behave somewhat like a hybrid of the lighter congeners but is significantly more reactive than either of them.

\section{Acknowledgements}

We thank Dr V. M. Lynch for help with the collection of X-ray crystallographic data, Professor S. F. Martin for the use of his SGI Octane workstation, and the Robert A. Welch Foundation for generous financial support (F-0003).

\section{References}

1 P. Jutzi and N. Burford, Chem. Rev., 1999, 99, 969-990.

2 (a) I. Resa, E. Carmona, E. Gutierrez-Puebla and A. Monge, Science, 2004, 305, 1136-1138; (b) D. del Rio, A. Galindo and I. Resa, Angew. Chem., Int. Ed., 2005, 44, 1244-1247; (c) A. Grirrane, I. Resa, A. Rodriguez, E. Carmona, E. Alvarez, E. Guitierrez-Puebla, A. Monge, A. Galindo, D. Del, Rio and R. A. Andersen, J. Am. Chem. Soc., 2007, 129, 693-703.

3 A. Togni and R. L. Halterman, Metallocenes: Synthesis, Reactivity, Applications, Wiley-VCH, New York, 1998, vol. 1 and 2.

4 M. Bochmann and D. M. Dawson, Angew. Chem., Int. Ed. Engl., 1996, 35, 2226-2228.

5 P. Jutzi and A. Seufert, J. Organomet. Chem., 1978, 161, C5-C7.

6 A. Voigt, S. Filipponi, C. L. B. Macdonald, J. D. Gorden and A. H. Cowley, Chem. Commun., 2000, 911-912. 
7 B. Dohmeier, H. Schnöckel, C. Robl, U. Schneider and R. Ahlrichs, Angew. Chem., Int. Ed. Engl., 1993, 32, 1655-1657.

8 C. Dohmeier, E. Baum, A. Ecker, R. Koeppe and H. Schnöckel, Organometallics, 1996, 15, 4702-4706.

9 D. Uffing, A. Ecker, E. Baum and H. Schnöckel, Z. Anorg. Allg. Chem., 1999, 625, 1354-1356.

10 C. T. Burns, D. S. Stelck, P. J. Shapiro, A. Vij, K. Kunz, G. Kehr, T. Concolino and A. L. Rheingold, Organometallics, 1999, 18, 5432-5434.

11 C. T. Burns, P. J. Shapiro, P. H. M. Budzelaar, R. Willett and A. Vij, Organometallics, 2000, 19, 3361-3367.

12 R. W. Schurko, I. Hung, C. L. B. Macdonald and A. H. Cowley, J. Am. Chem. Soc., 2002, 124, 13204-13214.

13 J. Vollet, J. R. Hartig, K. Baranowska and H. Schnöckel, Organometallics, 2006, 25, 2101-2103.

14 C. L. B. Macdonald, J. D. Gorden, A. Voigt and A. H. Cowley, J. Am. Chem. Soc., 2000, 122, 11725-11726.

15 P. Jutzi, B. Krato, M. Hursthouse and A. J. Howes, Chem. Ber., 1987, 120, 565-74.

16 S. Harder, Coord. Chem. Rev., 1998, 176, 17-66.

17 P. Jutzi, Chem. Unserer Z., 1999, 33, 342-353.

18 M. Del Mar Conejo, R. Fernandez, E. Gutierrez-Puebla, A. Monge, C. Ruiz and E. Carmona, Angew. Chem., Int. Ed., 2000, 39, 1949-1951.

19 R. W. Schurko, I. Hung, S. Schauff, C. L. B. Macdonald and A. H Cowley, J. Phys. Chem. A, 2002, 106, 10096-10107.

20 S. J. Lee, P. J. Shapiro and B. Twamley, Organometallics, 2006, 25, $5582-5586$.

21 J. D. Fisher, M.-Y. Wei, R. Willett and P. J. Shapiro, Organometallics, 1994, 13, 3324-9.

22 O. T. Beachley, Jr., R. B. Hallock, H. M. Zhang and J. L. Atwood, Organometallics, 1985, 4, 1675-80.

23 F. H. Allen, Acta Crystallogr., Sect. B: Struct. Sci., 2002, 58, 380-388.

24 P. H. M. Budzelaar, J. J. Engelberts and J. H. van Lenthe, Organometallics, 2003, 22, 1562-1576.

25 O. Kwon and M. L. McKee, J. Phys. Chem. A, 2001, 105, 10133-10138

26 M. M. Conejo, R. Fernandez, D. del Rio, E. Carmona, A. Monge and C. Ruiz, Chem. Commun., 2002, 2916-2917.

27 M. del Mar Conejo, R. Fernandez, D. del Rio, E. Carmona, A. Monge, C. Ruiz, A. M. Marquez and F. J. Sanz, Chem.-Eur. J., 2003, 9, 44524461.

28 L. C. Allen, J. Am. Chem. Soc., 1989, 111, 9003-9014.

29 H. Schumann, S. Nickel and R. Weimann, J. Organomet. Chem., 1994, 468, $43-47$.

30 S. Dagorne, I. A. Guzei, M. P. Coles and R. F. Jordan, J. Am. Chem. Soc., 2000, 122, 274-289.

31 T. Wondimagegn, Z. T. Xu, K. Vanka and T. Ziegler, Organometallics, 2005, 24, 2076-2085.

32 T. Wondimagegn, Z. T. Xu, K. Vanka and T. Ziegler, Organometallics, 2004, 23, 3847-3852.

33 S. P. Lewis, N. J. Taylor, W. E. Piers and S. Collins, J. Am. Chem. Soc., $2003,125,14686-14687$.
34 J. M. Zhou, S. J. Lancaster, D. A. Walker, S. Beck, M. ThorntonPett and M. Bochmann, J. Am. Chem. Soc., 2001, 123, 223237.

35 P. G. Lassahn, V. Lozan, B. Wu, A. S. Weller and C. Janiak, Dalton Trans., 2003, 4437-4450.

36 B. E. Bosch, G. Erker, R. Frohlich and O. Meyer, Organometallics, 1997, 16, 5449-5456.

37 U. Schneider and R. Ahlrichs, Chem. Phys. Lett., 1994, 226, 491-494.

38 P. Margl, K. Schwarz and P. E. Bloechl, J. Am. Chem. Soc., 1994, 116, 11177-8.

39 L. W. Mire, S. D. Wheeler, E. Wagenseller and D. S. Marynick, Inorg. Chem., 1998, 37, 3099-3106.

40 V. M. Rayon and G. Frenking, Chem.-Eur. J., 2002, 8, 46934707.

41 V. Quindt, D. Saurenz, O. Schmitt, M. Schar, T. Dezember, G. Wolmershauser and H. Sitzmann, J. Organomet. Chem., 1999, 579, 376-384.

42 H. Schmidbaur and W. Findeiss, Angew. Chem., 1964, 76, 752-3.

43 A. G. Massey and A. J. Park, J. Organomet. Chem., 1964, 2, 245250.

44 J. C. W. Chien, W.-M. Tsai and M. D. Rausch, J. Am. Chem. Soc., 1991, 113, 8570-8571.

45 P. Biagini, G. Lugli, L. Abis and P. Andreussi, Eur. Pat. Appl. EP 694,548 A1; Chem. Abs., 1996, 124, 232775.

46 A. Altomare, M. C. Burla, M. Camalli, G. Cascarano, C. Giacovazzo, A. Guagliardi, A. G. G. Moliterni, G. Polidori and R. Spagna, SIR97, CNR-IRMEC, Bari, 1997.

47 G. M. Sheldrick, SHELXS-97, Universitat Göttingen, Göttingen, 1997.

48 L. J. Farrugia, J. Appl. Crystallogr., 1999, 32, 837-838.

49 G. M. Sheldrick, SHELXTL, Bruker AXS Inc, Madison, WI, 2001.

50 A. L. Spek, J. Appl. Crystallogr., 2003, 36, 7-13.

51 M. J. Frisch, G. W. Trucks, H. B. Schlegel, G. E. Scuseria, M. A. Robb, J. R. Cheeseman, V. G. Zakrzewski, J. A. Montgomery, Jr., R. E. Stratmann, J. C. Burant, S. Dapprich, J. M. Millam, A. D. Daniels, K. N. Kudin, M. C. Strain, O. Farkas, J. Tomasi, V. Barone, M. Cossi, R. Cammi, B. Mennucci, C. Pomelli, C. Adamo, S. Clifford, J. Ochterski, G. A. Petersson, P. Y. Ayala, Q. Cui, K. Morokuma, P. Salvador, J. J. Dannenberg, D. K. Malick, A. D. Rabuck, K. Raghavachari, J. B. Foresman, J. Cioslowski, J. V. Ortiz, A. G. Baboul, B. B. Stefanov, G. Liu, A. Liashenko, P. Piskorz, I. Komaromi, R. Gomperts, R. L. Martin, D. J. Fox, T. Keith, M. A. Al-Laham, C. Y. Peng, A. Nanayakkara, M. Challacombe, P. M. W. Gill, B. Johnson, W. Chen, M. W. Wong, J. L. Andres, C. Gonzalez, M. Head-Gordon, E. S. Replogle and J. A. Pople, Gaussian 98, A.11.1 Gaussian Inc., Pittsburg, 2001.

52 A. D. Becke, Phys. Rev. A, 1988, 38, 3098-3100.

53 J. P. Perdew, Phys. Rev. B, 1986, 33, 8822-8824.

54 G. Schaftenaar and J. H. Noordik, J. Comput. Aided Mol. Des., 2000, 14, 123-134. 